\title{
18 $\alpha$-Glycyrrhetinic Acid Proteasome Activator Decelerates Aging and Alzheimer's Disease Progression in Caenorhabditis elegans and Neuronal Cultures
}

\author{
Nikoletta Papaevgeniou, ${ }^{1,2, *}$ Marianthi Sakellari, ${ }^{1,3,{ }^{*}}$ Sweta Jha, Nektarios Tavernarakis, ${ }^{5,6}$ Carina I. Holmberg, \\ Efstathios S. Gonos, ${ }^{1,3}$ and Niki Chondrogianni ${ }^{1}$
}

\begin{abstract}
Aims: Proteasomes are constituents of the cellular proteolytic networks that maintain protein homeostasis through regulated proteolysis of normal and abnormal (in any way) proteins. Genetically mediated proteasome activation in multicellular organisms has been shown to promote longevity and to exert protein antiaggregation activity. In this study, we investigate whether compound-mediated proteasome activation is feasible in a multicellular organism and we dissect the effects of such approach in aging and Alzheimer's disease (AD) progression.

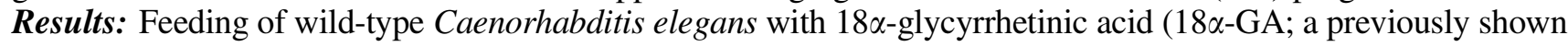
proteasome activator in cell culture) results in enhanced levels of proteasome activities that lead to a skinhead-1- and proteasome activation-dependent life span extension. The elevated proteasome function confers lower paralysis rates in various $\mathrm{AD}$ nematode models accompanied by decreased $\mathrm{A} \beta$ deposits, thus ultimately decelerating the progression of AD phenotype. More importantly, similar positive results are also delivered when human and murine cells of nervous origin are subjected to $18 \alpha$-GA treatment.

Innovation: This is the first report of the use of $18 \alpha-\mathrm{GA}$, a diet-derived compound as prolongevity and antiaggregation factor in the context of a multicellular organism.

Conclusion: Our results suggest that proteasome activation with downstream positive outcomes on aging and $\mathrm{AD}$, an aggregation-related disease, is feasible in a nongenetic manipulation manner in a multicellular organism. Moreover, they unveil the need for identification of antiaging and antiamyloidogenic compounds among the nutrients found in our normal diet. Antioxid. Redox Signal. 25, 855-869.
\end{abstract}

Keywords: proteasome activation, lifespan extension, aging, Alzheimer's disease, aggregation, proteostasis

\section{Introduction}

A GING IS A NATURAL PROCESS characterized by gradual deterioration of various molecular pathways, continuing loss of homeostatic integrity, and accumulated levels of damaged macromolecules that eventually result in increased death incidence (12). Its progression is dynamically affected by both genetic and environmental factors, and several hallmarks of aging have been suggested, including loss of proteostasis (37). Moreover, it is considered as a major risk factor for several pathologies, including aggregation-related disorders such as Alzheimer's disease (AD) (37). The various cellular proteolytic systems are among the major guardians of proteostasis, with the proteasome playing a catalytic role (16).

The proteasome is one of the two constituents of the ubiquitin-proteasome system (UPS, the other constituent being the ubiquitin system) responsible for the degradation of a pleiad of both normal and abnormal (in any way) proteins. The main proteasome core is called $20 \mathrm{~S}$ complex, a barrel-shaped

\footnotetext{
${ }^{1}$ Institute of Biology, Medicinal Chemistry and Biotechnology, National Hellenic Research Foundation, Athens, Greece.

${ }^{2}$ Faculty of Biology and Pharmacy, Institute of Nutrition, Friedrich Schiller University of Jena, Jena, Germany.

${ }^{3}$ Medical School, Orebro University, Örebro, Sweden.

${ }_{5}^{4}$ Translational Cancer Biology Program, Research Programs Unit, University of Helsinki, Helsinki, Finland.

${ }^{5}$ Institute of Molecular Biology and Biotechnology, Foundation for Research and Technology-Hellas, Heraklion, Greece.

${ }^{6}$ Faculty of Medicine, Department of Basic Sciences, University of Crete, Heraklion, Greece.

*These two authors contributed equally.
} 


\section{Innovation}

Proteasome activation is feasible in multicellular organisms exerting antiaging and antiaggregation activities. However, in all studies, activation has been succeeded via genetic overexpression of various proteasome subunits. This is the first report of the use of $18 \alpha$-glycyrrhetinic acid, a diet-derived compound with proteasome-activating properties serving as prolongevity and antiaggregation factor in a multicellular organism. Dietary available active compounds may be supplied through normal diet from young ages, thus having the potential to block the initial stages of misfolded/damaged/oxidized protein accumulation (for aging) or oligomer/aggregate formation (for Alzheimer's disease) before the senescent phenotype or the disease is established.

structure with seven different $\alpha$ - and seven different $\beta$ subunits, arranged in an $\alpha_{1-7} \beta_{1-7} \beta_{1-7} \alpha_{1-7}$ order. The complex carries the peptidylglutamyl peptide hydrolyzing (PGPH), trypsin-like (T-L), and chymotrypsin-like (CT-L) proteolytic activities hosted by $\beta_{1}, \beta_{2}$, and $\beta_{5}$ catalytic subunits, respectively, with CT-L being the major one. Upon attachment of one or two 19S regulatory complexes at the end of the 20S core, the $26 \mathrm{~S}$ and the $30 \mathrm{~S}$ complexes are produced to exert ATP- and ubiquitin-dependent degradation (59).

With the exception of the yeast regulatory particle nonATPase protein (RPN-4) that acts as the main proteasome transcription factor (38), proteasome subunit expression regulation in higher organisms, including humans, is not entirely elucidated. Several other factors have been implicated in the transcription of proteasome subunits under specific conditions, with skinhead-1 (SKN-1, in Caenorhabditis elegans)/nuclear factor (erythroid-derived 2)-like 2 (Nrf2, in mammals) being one of them $(26,34)$. More specifically, $\mathrm{SKN}-1 / \mathrm{Nrf} 2$ is implicated in the induction of genes involved in electrophile detoxification and antioxidation, thus regulating the cellular response to oxidative stress (56). Upon proteasome inhibition, $\mathrm{SKN}-1$ translocates to the nucleus to induce proteasome subunit expression $(26,35)$. Likewise, most of the mammalian proteasome genes are regulated by Nrf2 in response to antioxidants such as 3H-1,2-dithiole-3thione (D3T) (34). We have previously shown that SKN-1 is involved in proteasome activation in $C$. elegans following $p b s$-5 overexpression (8). Moreover, treatment of human fibroblasts with $18 \alpha$-glycyrrhetinic acid ( $18 \alpha-\mathrm{GA})$ triterpenoid promotes Nrf 2 activation, leading to proteasome activation, and enhanced cellular stress resistance and life span (27). Therefore, compound-mediated targeting of Nrf2 is a plausible strategy to achieve proteasome upregulation.

Proteasome levels and/or function have been documented to decline with aging in vitro and in vivo (12), as well as during several age- and aggregation-related diseases, including $\mathrm{AD}$ (47). On the other hand, proteasome activation has been suggested as a potential antiaging (9) and retardation strategy against the progression of age-related diseases (16). Lately, proteasome activation was achieved in multicellular organisms through genetic manipulation of either $20 \mathrm{~S}$ or $19 \mathrm{~S}$ subunits with positive outcomes on aging, stress resistance, and aggregation-related neuropathies $(8,55,58)$. Given the restraints of genetic manipulation in humans, identification of proteasome-activating compounds is needed to promote proteasome enhancement ideally through human normal diet.

In this study, we sought to investigate whether compoundmediated proteasome activation is feasible in a multicellular model system using $C$. elegans. We provide evidence that treatment with $18 \alpha$-GA [a previously identified proteasome activator in cell culture; (27)] induces proteasome enhancement leading to an SKN-1- and proteasome activation-dependent life span extension. We also demonstrate that $18 \alpha$-GA treatment affects $\mathrm{AD}$ progression in a proteasome activation-dependent manner in various AD nematode models and in cells of nervous origin. In total, our results demonstrate the potential use of $18 \alpha-$ GA as a prolongevity and antiaggregation compound.

\section{Results}

\section{$18 \alpha-G A$ confers proteasome activation in C. elegans}

We have previously shown that $18 \alpha$-GA treatment of human fibroblasts induces proteasome activation and results in extended cellular life span (27). We therefore aimed to examine whether this is an in vitro cell-specific effect or whether it may be exerted in a multicellular organism, namely C. elegans. Wild-type (wt) animals were treated with various concentrations of $18 \alpha-\mathrm{GA}$; CT-L and T-L proteasome activities were significantly enhanced (Fig. 1A). In-gel activity assay verified the enhancement of both $20 \mathrm{~S}$ and $26 \mathrm{~S} / 30 \mathrm{~S}$ proteasome activities (Fig. 1B). By taking advantage of a fluorescent in vivo polyubiquitin reporter system that responds to changes in proteasome activity (40), we also observed induced UPS activity in vivo (Fig. 1C). Protein expression analysis of PAS-1-7, PBS-5, and RPT-6 subunits revealed increased levels (Fig. 1D), correlating with the detected enhanced activity. Collectively, our results show that $18 \alpha$-GA promotes proteasome activation in the context of a multicellular organism.

\section{$18 \alpha-G A$ promotes life span extension in a SKN-1- and proteasome activation-dependent manner}

Since compound-mediated proteasome enhancement is a desired goal in the proteasome and antiaging field, we sought to investigate whether the observed $18 \alpha$-GA-mediated proteasome activation promotes life span extension in C. elegans. Significant life span enhancement was revealed with the most effective concentration being $20 \mu \mathrm{g} / \mathrm{ml}$ (Fig. 2A and Supplementary Fig. S1A, B; Supplementary Data are available online at www.liebertpub.com/ars). We have also investigated whether $18 \alpha$-GA treatment confers any phenotypic differences (Table 1). Pharyngeal pumping, defecation rhythm, fecundity, and capacity to enter the stress-resistant dauer larvae form remained unaffected. We only observed a slightly delayed embryonic development, which has also been seen in long-lived strains (60).

The transcription factor, $\mathrm{SKN}-1$, has been shown to be essential for life span regulation $(3,56)$ and has been correlated with the proteasome $(26,35,45)$. Having shown that $18 \alpha$-GA treatment activates Nrf 2 in human primary cells (27), we tested whether it also affects SKN-1. Use of a reporter fusion of SKN-1 (skn-1B/C::GFP) revealed its nuclear translocation in the intestinal cells of $18 \alpha$-GA-treated animals (Fig. 2B). Immunoblot analysis of the activated form of p38 MAPK revealed p38 MAPK kinase phosphorylation 
A

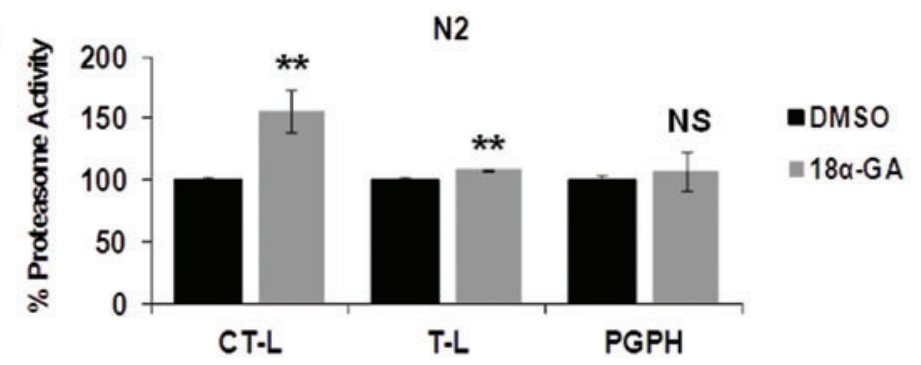

FIG. 1. 18 $\alpha$-GA-mediated proteasome activation. (A) Percentage (\%) of CT-L, $\mathrm{T}-\mathrm{L}$, and PGPH proteasome activities in wt animals treated with $20 \mu \mathrm{g} / \mathrm{ml} 18 \alpha-\mathrm{GA}$ or DMSO. Mean value of each activity in DMSO-treated animals set to $100 \%$. (B) Native gel electrophoresis, followed by ingel proteasome activity assay and quantification (right panel; signal from $20 \mathrm{~S}$ or $30 \mathrm{~S} /$ 26S complex in DMSO-treated animals set as 1) in wt animals treated with $20 \mu \mathrm{g} / \mathrm{ml}$ $18 \alpha-G A$ or DMSO. (C) Representative fluorescence micrographs of animals expressing the polyubiquitin reporter (Pvha$6: \because$ UIM2-ZsPro-Sensor) in the intestine treated with $20 \mu \mathrm{g} / \mathrm{ml} 18 \alpha-\mathrm{GA}$ or DMSO. (D) Immunoblot analysis and quantification of PAS-1-7, PBS-5, and RPT-6 proteasome subunits in wt animals treated with $20 \mu \mathrm{g} / \mathrm{ml}$ $18 \alpha-\mathrm{GA}$ or DMSO. Actin in (B) and (D) was used as a loading control. Error bars denote \pm SEM. $* * p<0.01, * * * p<0.001$. $18 \alpha-\mathrm{GA}, 18 \alpha-$ glycyrrhetinic acid; CT-L, chymotrypsin-like; DMSO, dimethyl sulfoxide; NS, not significant; PGPH, peptidylglutamyl peptide hydrolyzing; SEM, standard error of the mean; T-L, trypsin-like; wt, wild-type. To see this illustration in color, the reader is referred to the web version of this article at www.liebertpub .com/ars
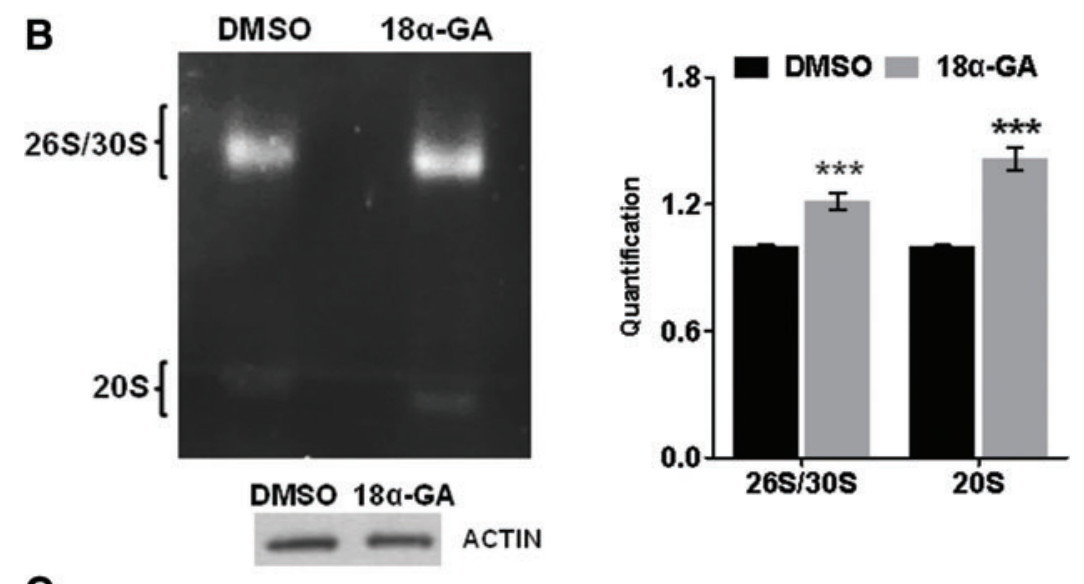

C

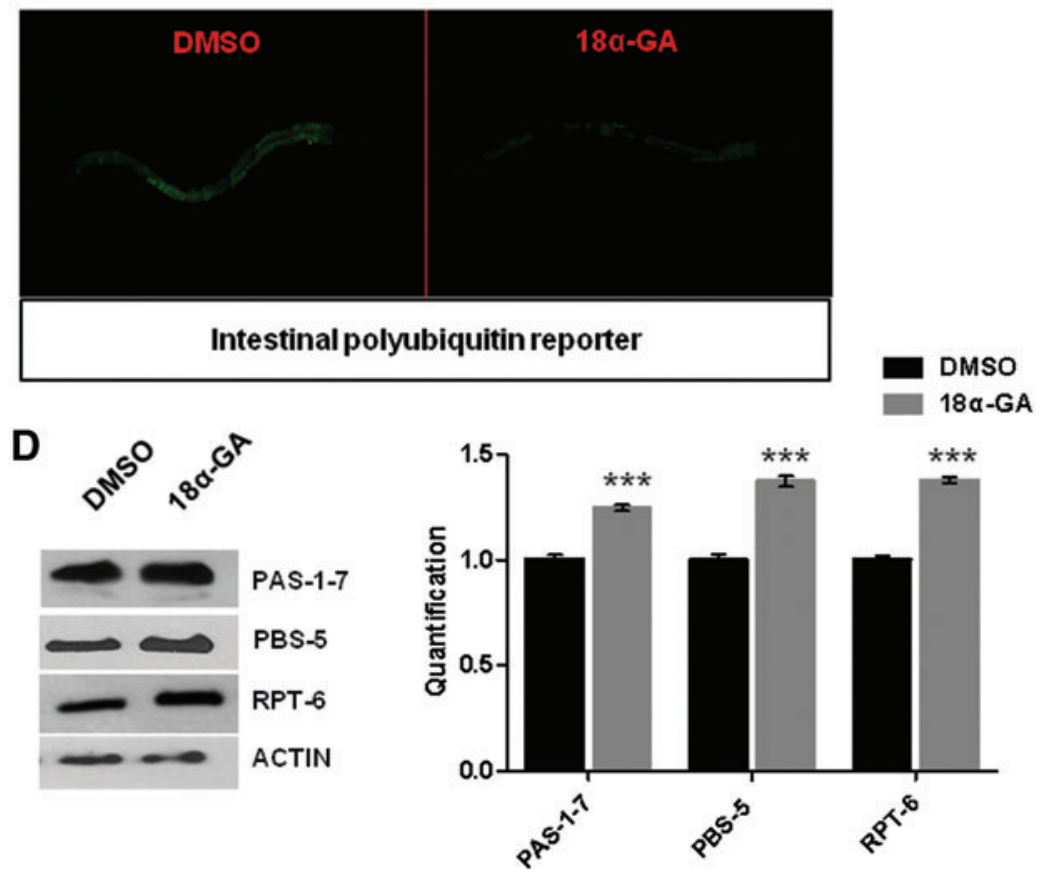

following $18 \alpha$-GA treatment (Supplementary Fig. S2), leading to SKN-1 activation (25). We then employed three different skn-1 mutant strains [EU1, EU31, and EU40, bearing premature stop codon mutations; (56)] to reveal the potential SKN-1 dependence of the observed life span extension; $18 \alpha-$ GA failed to extend the life span of all three homozygous $s k n-1$ mutants (Fig. 2C), thus verifying SKN-1 implication. Interestingly, lifetime $18 \alpha-\mathrm{GA}$ treatment of heterozygous $s k n-1$ mutants resulted in extended life span, suggesting that even only one normal $s k n-1$ allele is sufficient for the life span- extending action of the compound (Fig. 2D). In support, knockdown of $s k n-1$ (Fig. 2E; compare dimethylsulfoxide [DMSO] [skn-1 RNA interference [RNAi] with 18 $\alpha$-GA [skn1 RNAi]) or $p b s-5$ (Fig. 2F; compare DMSO [pbs-5 RNAi] with $18 \alpha-\mathrm{GA}$ [ $p b s-5$ RNAi]) by RNAi abolished this extension. Accordingly, CT-L proteasome activity in EU1 mutant was not enhanced following 18 $\alpha$-GA treatment (Fig. 2G). Given that DAF-16/FOXO transcription factor is also a major aging regulator in $C$. elegans (30), we have also investigated whether this extension is DAF-16 dependent; $18 \alpha-\mathrm{GA}$ did not 
extend the life span of daf-16 mutants, thus suggesting DAF16 dependence (Supplementary Fig. 1C). In total, our results indicate that $18 \alpha$-GA treatment promotes life span extension in a $s k n-1$ - and proteasome activation-dependent manner.

Oxidatively modified proteins are removed by the proteasome (49). Treatment with $18 \alpha$-GA for 48,72 , and $96 \mathrm{~h}$ resulted in reduction of the carbonylated proteins by $18 \%$, $44 \%$, and $40 \%$, respectively (Fig. 3A). These decreased levels may be due either to the increased proteasome activity levels or to the antioxidant activity of $18 \alpha-\mathrm{GA}$. When superoxide dismutase (SOD) activity was evaluated, we did not detect any alterations in the intracellular superoxide anion $\left(\mathrm{O}_{2}{ }^{-}\right)$ levels in contrast to the positive control (tetracycline; Fig. 3B). In accordance, monitoring of the reporter $\mathrm{p}_{\text {sod-3 }} G F P$ following $18 \alpha$-GA treatment did not reveal significant alterations, thus verifying the lack of sod-3 induction (data not shown). In contrast, catalase activity was found to be increased in $18 \alpha$-GA-treated animals (Fig. 3C). Furthermore, the RNA expression levels of various SKN-1 target genes (glutathione $S$-transferase [gst-4] and $\gamma$-glutamylcysteine synthetase $[\mathrm{gcs}-1]$ ) were altered in opposite ways following $18 \alpha$-GA treatment, whereas all proteasome subunits tested were induced (Fig. 3D). Finally, we did not detect oxidative stress resistance of wt animals in paraquat (a generator of $\mathrm{O}_{2}^{-}$; Fig. 3E) or juglone (that produces damaging adducts with proteins; Fig. 3F). Our data suggest that the positive outcomes of $18 \alpha$-GA may not be solely related to its antioxidant activity per se and may advocate for the link between the observed lower amounts of oxidized proteins and the increased levels of proteasome activity.

\section{8 $\alpha$-GA-mediated proteasome activation delays aggregation-related pathologies}

Aging represents a crucial risk factor for aggregationrelated disorders $(12,43)$. Moreover, proteasome inhibition and diminished proteasome activities have been monitored in AD patients $(29,57)$. We therefore investigated the effects of $18 \alpha$-GA-mediated proteasome activation on AD progression by taking advantage of three different nematode AD models. More specifically, paralysis assays in CL2006 strain [constitutive expression of human $\mathrm{A} \beta_{1-42}$ in body wall muscle cells with adult-onset paralysis accompanied by $\beta$-amyloid formation; (36)] revealed a significant delay of paralysis upon $18 \alpha$-GA treatment (Fig. 4A). Similar results were obtained in CL4176 strain [temperature-sensitive expression of human $\mathrm{A} \beta_{1-42}$ resulting in $\beta$-amyloid formation; (20); Fig. 4B]. More importantly, combined treatment with $p b s-5$ RNAi and $18 \alpha$-GA abolished the delayed paralysis (Fig. 4C), thus advocating for the dependence of the decelerated paralysis rates on proteasome activation. Protein expression analysis of various 19S and 20S proteasome subunits further verified the $18 \alpha$-GA-mediated enhancement of proteasome levels (Fig. 4D) similarly to the results in wt animals (Fig. 1D). Finally, lifetime $18 \alpha$-GA treatment resulted in significant life span extension of CL2006 animals (where age-dependent aggregation and paralysis occur; Fig. 4E). Collectively, our results suggest that $18 \alpha-\mathrm{GA}$ promotes deceleration of the AD paralysis phenotype in a proteasome activation-dependent manner.

To evaluate the $\mathrm{A} \beta$ aggregation state in vivo, we took advantage of CL2331 strain (temperature-sensitive expression of human $\mathrm{A} \beta_{3-42}$ conjugated with GFP in the body wall muscle cells); $18 \alpha$-GA treatment confers a significant reduction of $\mathrm{A} \beta$ deposits (Fig. 5A; red panels and arrows and Fig. 5B). We did not observe any differences in the GFP production upon $18 \alpha$-GA or DMSO treatment in the CL2179 control strain (data not shown). We have also revealed significant reduction of total $\mathrm{A} \beta$ levels in CL4176 animals upon $18 \alpha$-GA treatment (Fig. 5C upper and middle panels), while pbs-5 knockdown drastically reduced this positive outcome (Fig. 5C compare middle and lower panels). We suggest that these decreased levels are due to the $18 \alpha$-GA-mediated enhanced proteasome function.

Finally, we sought to evaluate whether $18 \alpha$-GA treatment may protect neuronal cells against $\mathrm{A} \beta$ toxicity. We took advantage of SH-SY5Y human neuroblastoma cells that were exposed to 7PA2-conditioned medium $\left(\mathrm{CM}, \mathrm{CM}_{\mathrm{A} \beta}\right.$; contains $\mathrm{A} \beta)$ in the presence of $18 \alpha-\mathrm{GA}$ or DMSO. We initially verified that $18 \alpha-\mathrm{GA}$ induces proteasome activation in those cells and conditions (Fig. 6A). Parallel treatment of SH-SY5Y exposed to $\mathrm{CM}_{\mathrm{A} \beta}$ with $18 \alpha-\mathrm{GA}$ led to a significantly reduced cell death and increased cell survival compared with the control cultures (Fig. 6B1, B2). Treatment with $\mathrm{CM}_{\text {control }}$ (no $\mathrm{A} \beta$ production) did not reveal any differences (data not shown). Dot blot analysis revealed reduced levels of total $\mathrm{A} \beta$ upon $18 \alpha-\mathrm{GA}$

FIG. 2. 18 $\alpha$-GA promotes life span extension of wt Caenorhabditis elegans in a SKN-1- and proteasome activationdependent manner. Survival curves of (A) wt C. elegans, (C) homozygous (-/-) skn-1 mutants, and (D) heterozygous (+/-) $s k n-1$ mutants treated with $20 \mu \mathrm{g} / \mathrm{ml} 18 \alpha$-GA or DMSO. (A) DMSO: mean $=15.6 \pm 0.8, n=657 / 866 ; 18 \alpha-\mathrm{GA}$ : mean $=18.3$ $\pm 1.2, n=575 / 827, p<0.0001$; (C) DMSO EU1 $(-/-)$ : mean $=13.5 \pm 0.5, n=86 / 173 ; 18 \alpha-$ GA EU1 $(-/-)$ : mean $=13.5 \pm 0.5$, $n=84 / 173 ; N S$. DMSO EU40 (-l-): mean $=16.3 \pm 0.9, n=173 / 293 ; 18 \alpha-G A$ EU40 (-l-): mean $=17 \pm 0.6, n=180 / 292 ; N S$. DMSO EU31 (-/-): mean $=19.5 \pm 5.5, n=135 / 164 ; 18 \alpha-$ GA EU31 (-/-): mean $=18 \pm 4, n=112 / 161, N S$. (D) DMSO EU1 $(+/-)$ : mean $=11 \pm 1, n=143 / 195 ; 18 \alpha-G A$ EU1 $(+/-)$ : mean $=16.5 \pm 0.5, n=141 / 203, p<0.0001$; DMSO EU40 (+/-): mean $=12 \pm 1, n=115 / 167 ; 18 \alpha-$ GA EU40 $(+/-)$ : mean $=18 \pm 0, n=110 / 152, p=0.0002$; DMSO EU31 $(+/-)$ : mean $=11 \pm 1$, $n=137 / 171 ; 18 \alpha-$ GA EU31 (+/-): mean $=16 \pm 1, n=142 / 174, p<0.0001$. (B) Percentage of cytosolic, intermediate, or nuclear accumulation of SKN-1B/C::GFP in wt animals treated with $20 \mu \mathrm{g} / \mathrm{ml} 18 \alpha-\mathrm{GA}$ or DMSO. Survival curves of wt animals subjected to RNAi for (E) $s k n-1$ or the empty vector and (F) pbs-5 or the empty vector treated with $20 \mu \mathrm{g} / \mathrm{ml} 18 \alpha-\mathrm{GA}$ or DMSO. DMSO (vector) and $18 \alpha-\mathrm{GA}$ (vector) are common in (E) and (F) DMSO (vector): mean $=22.3 \pm 0.3, n=219 / 275 ; 18 \alpha-$ GA (vector): mean $=23.7 \pm 0.3, n=221 / 301, p<0.0001$; (E) DMSO (skn-1 RNAi): mean $=20 \pm 0, n=157 / 185 ; 18 \alpha-G A(s k n-1$ RNAi): mean $=20.5 \pm 0.5, n=180 / 213, N S$. (F) DMSO ( $p b s-5$ RNAi): mean $=11 \pm 0.1, n=88 / 107$; $18 \alpha-G A(p b s-5$ RNAi): mean $=11 \pm 0.1, n=91 / 105, N S$. (G) Percentage (\%) of CT-L proteasome activity in EU1 (-/-) animals treated with $20 \mu \mathrm{g} / \mathrm{ml}$ $18 \alpha$-GA or DMSO. Mean value of each activity in DMSO-treated animals set to $100 \%$. Error bars denote \pm SEM. $* p<0.05$. RNAi, RNA interference; SKN-1, skinhead-1. 
A

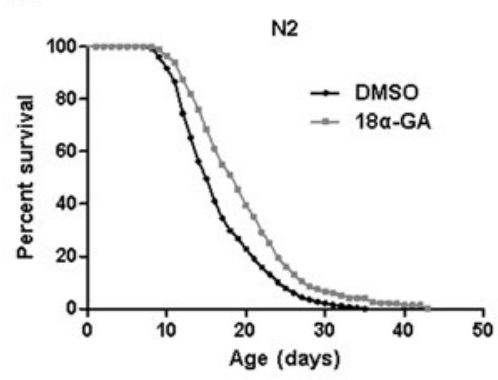

B SKN-1B/C::GFP

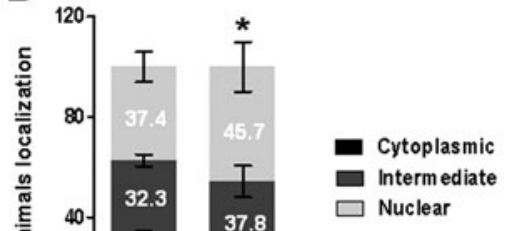

16.5 $\square$ Interm ediate

$\square$ Nuclear

$0^{50} x^{\circ} 0^{\circ}$
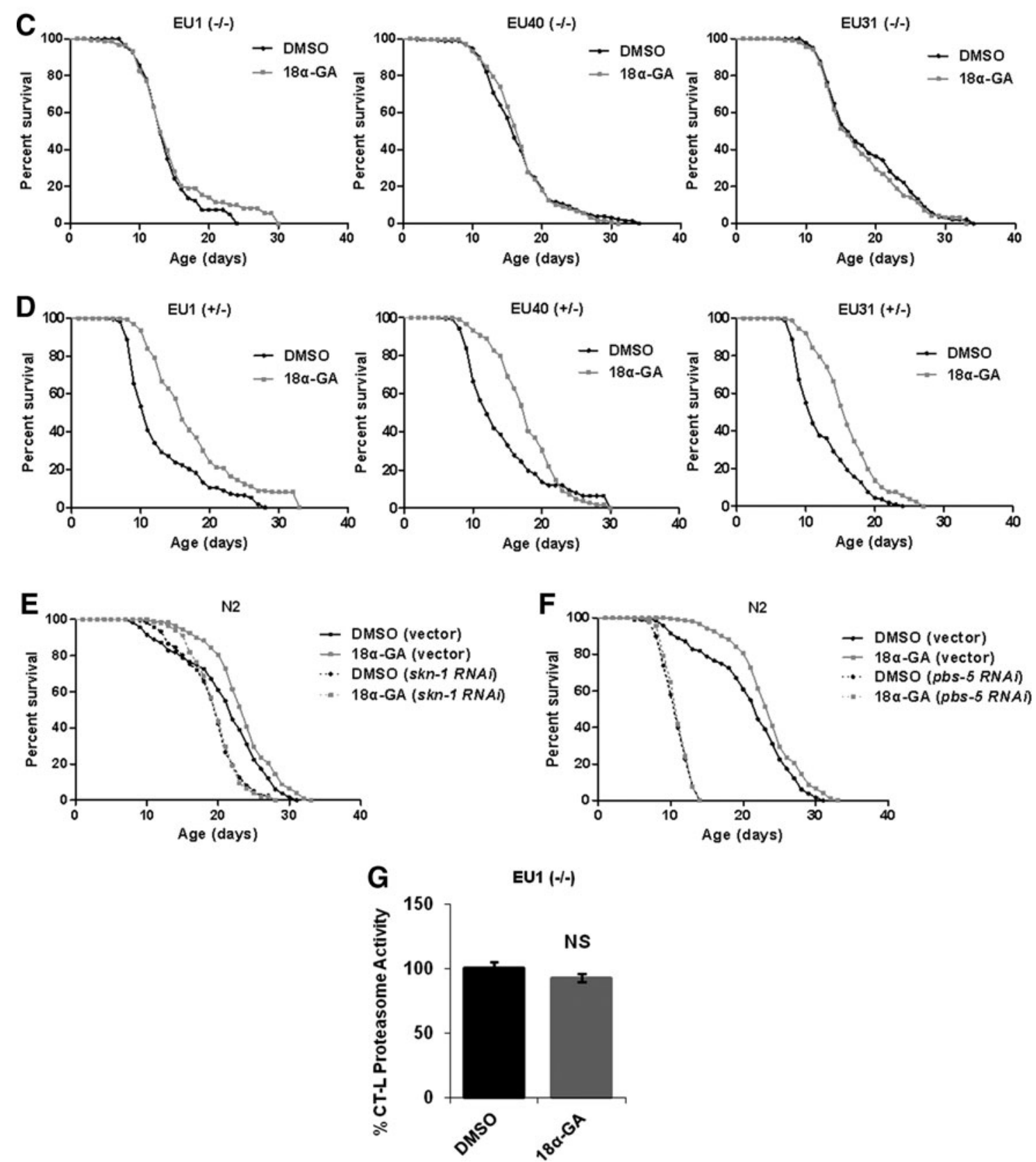
Table 1. Phenotypic Analysis of Wild-Type Animals Treated With $20 \mu \mathrm{g} / \mathrm{ML}$ $18 \alpha$-GlyCYRRHETINIC ACID OR Dimethyl SulfoXIDE

\begin{tabular}{lcccrr}
\hline & Fecundity $^{\mathrm{a}}$ & $\begin{array}{c}\text { Developmental } \\
\text { timing }^{\mathrm{b}, * * *}\end{array}$ & $\begin{array}{c}\text { Pharyngeal } \\
\text { pumping }^{\mathrm{c}}\end{array}$ & Defecation $^{\mathrm{d}}$ & $\boldsymbol{r}^{\text {Dauer }}$ \\
\hline DMSO & $255 \pm 36$ & $55.2 \pm 0.4$ & $62.5 \pm 1.5$ & $45.2 \pm 6.4$ & $0.5 \pm 0.7$ \\
$18 \alpha-\mathrm{GA}$ & $266 \pm 47$ & $56.9 \pm 0.3$ & $62.1 \pm 2$ & $46.9 \pm 5.2$ & $2 \pm 1.6$ \\
\hline
\end{tabular}

All assays were performed at $20^{\circ} \mathrm{C}$ unless noted otherwise.

${ }^{a}$ Number of offspring per worm.

${ }^{\mathrm{b}}$ Duration of postembryonic development (hours from egg hatching to L4 stage).

${ }^{c}$ Pumps in 15 s at day 1 of adulthood.

${ }^{\mathrm{d}}$ Duration of defecation cycle in seconds.

${ }^{\mathrm{e}}$ Percentage of animals becoming dauer larva at $27^{\circ} \mathrm{C}$.

$* * * p<0.001$.

$18 \alpha$-GA, $18 \alpha$-glycyrrhetinic acid; DMSO, dimethyl sulfoxide.

treatment, whereas proteasome inhibition by MG132 abolished this reduction (Fig. 6C). The protective role of $18 \alpha-\mathrm{GA}$ against $\mathrm{A} \beta$ toxicity was also verified in primary murine cortical neurons (Fig. 6D1-E). In conclusion, 18 $\alpha$-GA-mediated proteasome activation appears to be protective against $\mathrm{A} \beta$ proteotoxicity in nematodes and neuronal cells.

\section{Discussion}

Continuously growing evidence indicates that proteasome activation is a key mediator of enhanced cellular and organismal healthspan and life span. In this study, we show that compound-mediated proteasome activation is possible in C. elegans promoting the extension of its life span in a SKN1-dependent proteasome enhancement manner. We further show that this activation exerts beneficial effects on $\mathrm{AD}$ progression in relevant nematode models and in human and murine cells of nervous origin exposed to human $\mathrm{A} \beta$ peptide. This report reveals the potential antiaging and antiaggregation effects of a diet-derived compound.

Proteasomes are central players that need to be functional to preserve proteostasis (37). Given that proteasome function declines upon aging and senescence (12-14), proteasome activation has immerged as a promising approach for delaying aging and age-related diseases (16). Genetic activation has been achieved in cells, uni- and multicellular organisms (16), but the new trend is the identification of proteasomeactivating compounds. Various compounds have been identified so far, while several among them have been examined in the context of aging or age-related diseases (16). Few of them promote proteasome activation in multicellular organisms, including quercetin (21), catechin-enriched green tea extract (18), plant extracts from blackberries, hibiscus, elderberries, or jiaogulan (22) in nematodes and sulforaphane and D3T in mice $(33,34)$. In this study, we propose the triterpenoid, $18 \alpha-\mathrm{GA}$, as such compound. It is a pentacyclic triterpene glycoside considered as the most important bioactive compound derived from Glycyrrhiza radix (61). Although various properties have been attributed to $18 \alpha-\mathrm{GA}$, including not only anti-inflammatory (41) and anticancer/ proliferative (54) but also proproliferative on primary cells (31), we are the first to show its effects on organismal aging as a consequence of SKN-1-mediated proteasome activation.

Our data indicate that $18 \alpha-\mathrm{GA}$ treatment results in proteasome activation-dependent life span extension in $\mathrm{wt}$ nematodes. The observed dependence is in agreement with studies in human $(10,15,27)$ and yeast cells $(7,32)$ and in multicellular organisms $(8,46,55,58)$. It is, however, noteworthy that with the exception of quercetin (10) and $18 \alpha-\mathrm{GA}$ (27) in all other mentioned studies, proteasome activation was achieved through genetic manipulation. The crucial interdependence between enhanced proteasome function and prolongevity effects is also supported by reports in centenarians and naked mole rats, both known for their elongated life span and their increased proteasome function $(11,48,53)$.

The lower detected levels of carbonylated proteins [widely used as markers of aging; (1)] advocate for the prolongevity effects of $18 \alpha-\mathrm{GA}$. Both increased proteolysis rates due to proteasome activation and antioxidation may contribute to this reduction. Our data regarding the antioxidant properties of $18 \alpha-\mathrm{GA}$ reveal a complex regulation since genes of the same pathway such as gcs-1 and gst-4 (both known SKN-1 targets) or enzymatic activities of the same biochemical pathway such as SOD and catalase are altered in different ways. Those results coincide with recent studies showing increased complexity in the regulation of phase 2 detoxification systems and stress resistance in animals that involves additional SKN-1 independent regulators $(17,44)$. Therefore, the lack of stress resistance to oxidative stressors might be explained under this prism; maybe just SKN-1 induction is not enough for stress resistance under harsh oxidative stress.

SKN-1 possesses a central role in longevity and oxidative stress resistance $(3,56)$, thus implying that life span extension is anticipated upon its activation. Our data show that the $18 \alpha$ GA-mediated proteasome activation is SKN-1 dependent in accordance with the Nrf2 dependence of the same compound in human cells (27). We show that SKN-1 activation occurs through the p38 MAPK pathway (25). Likewise, at least partial SKN-1 dependence has been suggested upon pbs-5 overexpression-mediated proteasome activation (8). Nevertheless, our current study specifies proteasome activation as the main executer for the observed extended life span; the $18 \alpha$-GA prolongevity effects are lost if proteasome activation is impeded, despite SKN-1 activation.

We show that $18 \alpha$-GA-mediated proteasome enhancement confers protection against proteotoxic stress not only in AD nematode models but also in neuronal cells treated with $\mathrm{A} \beta$ peptide, probably through proteasomal degradation of (at least some) $\mathrm{A} \beta$ species. In support, genetically mediated proteasome activation was shown to protect against polyglutamine- 

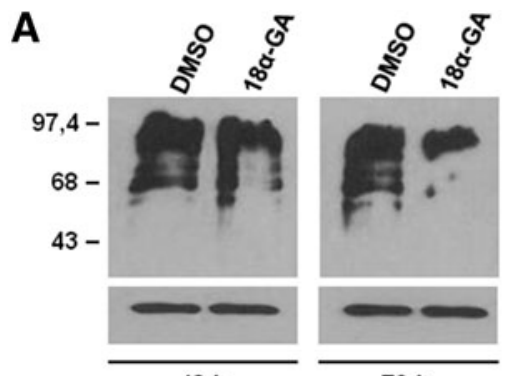

$72 \mathrm{~h}$
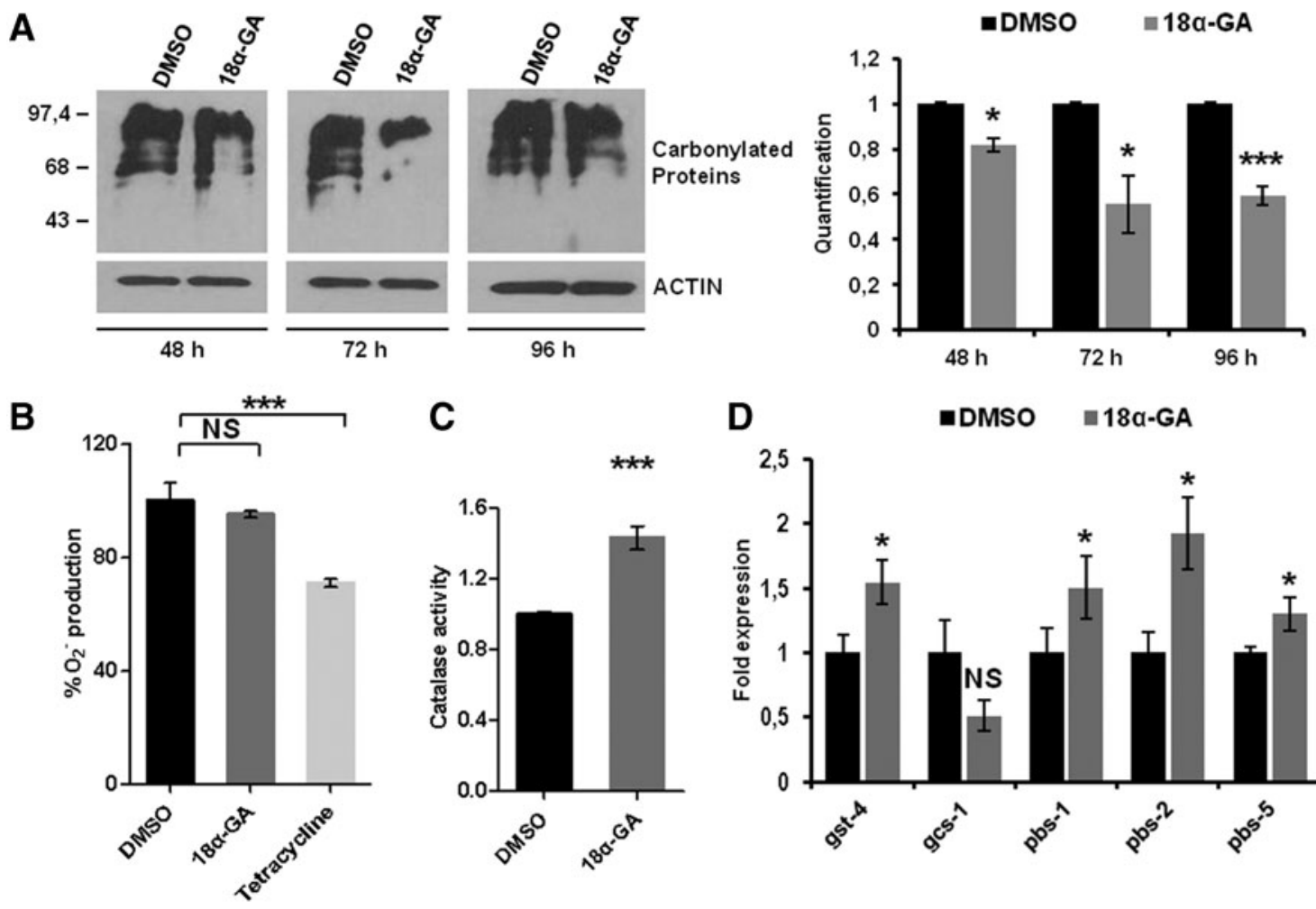

C

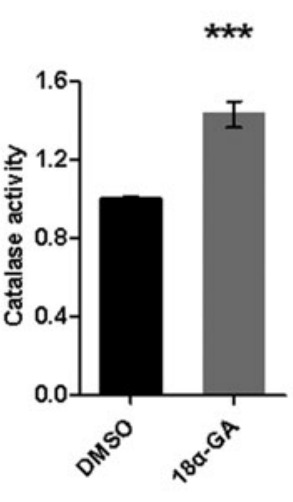

D
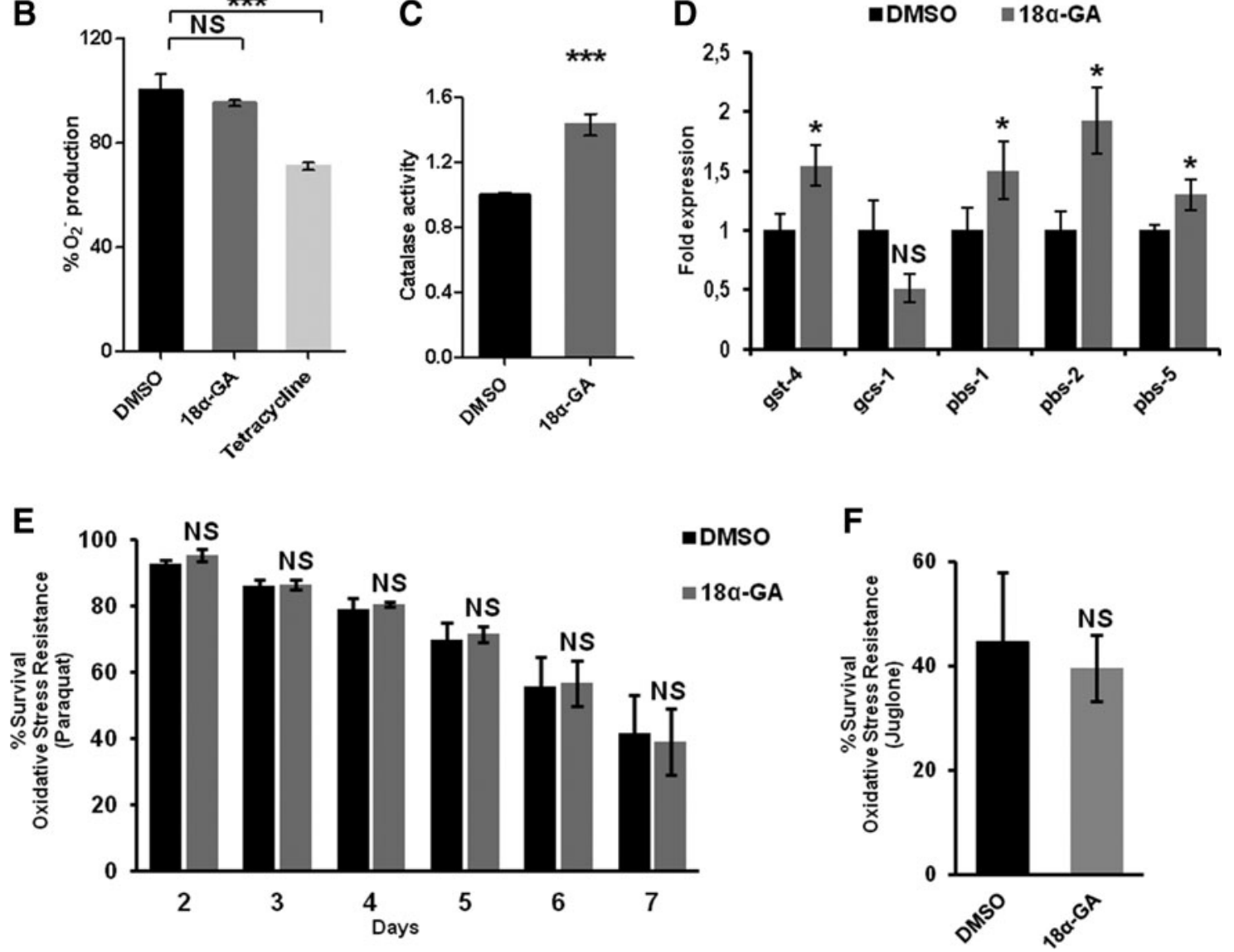

FIG. 3. Redox status in 18 $\alpha$-GA-treated animals. (A) Oxyblot analysis and quantification of carbonylated proteins in wt animals treated with $20 \mu \mathrm{g} / \mathrm{ml} 18 \alpha-\mathrm{GA}$ or DMSO for 48,72 , and $96 \mathrm{~h}$. MW markers containing 1-3 DNP residues/molecule are shown on the left. Actin was used as a loading control. (B) Percentage (\%) of superoxide anion production (mean value of $\mathrm{O}_{2}{ }^{-}$ production in DMSO-treated animals set to $100 \%$, tetracycline was used as positive control for antioxidant activity), (C) catalase activity (mean value of catalase activity in DMSO-treated animals set to 1), and (D) real-time polymerase chain reaction analysis of $g s t-4, g c s-1, p b s-1, p b s-2$, and $p b s-5$ genes (expression levels of each gene were arbitrarily set to 1 in DMSO-treated animals, pmp-3 gene expression was used as normalizer) in wt animals treated with $20 \mu \mathrm{g} / \mathrm{ml} 18 \alpha$-GA or DMSO. Percent survival of wt animals treated with $20 \mu \mathrm{g} / \mathrm{ml} 18 \alpha-\mathrm{GA}$ or DMSO (E) from L4 stage to day 5 of adulthood and then exposed to paraquat and scored from day 2 to 7 after paraquat exposure (four independent experiments, 500 animals/condition) and (F) from L4 stage to day 1 of adulthood and then exposed to juglone and scored following a 24-h recovery period (four independent experiments, 160 animals/ condition). Error bars denote \pm SEM. ${ }^{*} p<0.05, * * * p<0.0001$. DNP, dinitcophenyl; $g c s-1, \gamma$-glutamylcysteine synthetase; $g s t-4$, glutathione $S$-transferase; MW, molecular weight; $\mathrm{O}_{2}^{-}$, superoxide anions.

and $\mathrm{A} \beta$-induced toxicity $(8,55,58)$. Accordingly, several compounds have been shown to improve proteotoxic stress resistance in a proteasome-dependent manner. For example, quercetin supplementation delays the $\mathrm{A} \beta$-induced paralysis in an AD nematode model dependently on enhanced proteasome degradation (52). Likewise, a proteasome-dependent anti- amyloidogenic activity has been attributed to resveratrol (39, 51), ganoderic acid DM (6), thioflavin-T (2), and rolipram (42). Oleuropein aglycone was found to delay paralysis through $\mathrm{A} \beta$ deposit reduction in an $\mathrm{AD}$ nematode model (19) and to exert antiaggregation and neuroprotective activity in an $\mathrm{AD}$ mouse model (24) and in rats coinjected with $\mathrm{A} \beta_{42}$ (24). 

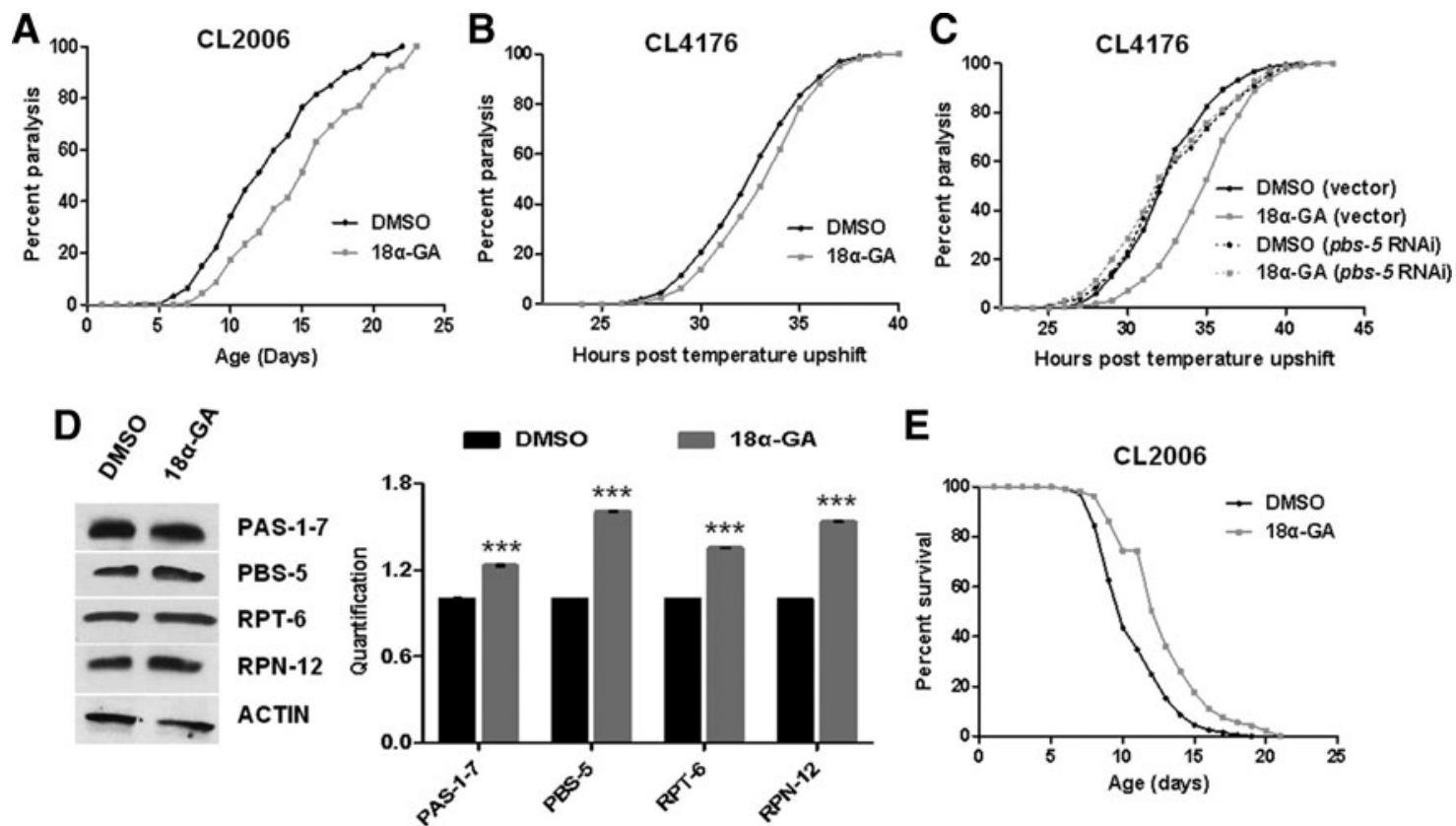

E

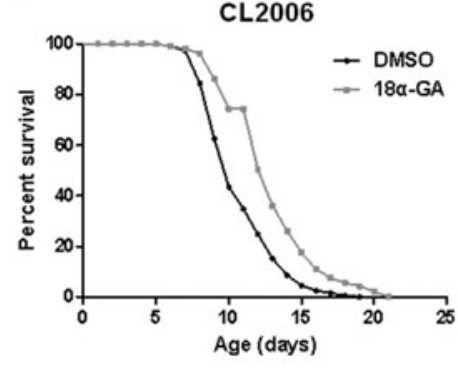

FIG. 4. 18 $\boldsymbol{\alpha}$-GA reduces A $\boldsymbol{\beta}$ toxicity. Paralysis curves of animals expressing human A $\beta_{1-42}$ peptide (A) CL2006 strain, (B) CL4176 strain, and (C) CL4176 strain subjected to RNAi for $p b s-5$ or the empty vector treated with $20 \mu \mathrm{g} / \mathrm{ml} 18 \alpha$-GA or DMSO. (A) DMSO: $\operatorname{mean}=12.3 \pm 0.3, n=163 / 333$; $18 \alpha$-GA: $\operatorname{mean}=15.6 \pm 0.6, n=134 / 332, p<0.0001$; (B) DMSO: mean $=32.5 \pm 0.2, n=1707 / 1717 ; 18 \alpha-G A$ : mean $=33.5 \pm 0.2, n=1691 / 1703, p<0.0001$; (C) DMSO (vector): mean $=33 \pm$ $0.2, n=564 / 575 ; 18 \alpha-G A$ (vector): mean $=35 \pm 0.2, n=654 / 666, p<0.0001$; DMSO ( $p b s-5$ RNAi): mean $=33 \pm 0.2$, $n=592 / 600$; $18 \alpha$-GA ( $p b s-5$ RNAi): mean $=32 \pm 0.2, n=588 / 598$, $N S$. (D) Immunoblot analysis and quantification of PAS1-7, PBS-5, RPT-6, and RPN-12 proteasome subunits in animals expressing human A $\beta_{1-42}$ peptide (CL2006 strain) treated with $20 \mu \mathrm{g} / \mathrm{ml} 18 \alpha$-GA or DMSO. Actin was used as a loading control. (E) Survival curve of animals expressing human $\mathrm{A} \beta_{1-42}$ peptide (CL2006 strain) treated with $20 \mu \mathrm{g} / \mathrm{ml} 18 \alpha$-GA or DMSO. DMSO: mean $=11 \pm 1.0, n=203 / 252 ; 18 \alpha-G A$ : mean $=13 \pm 0.0, n=186 / 258, p<0.0001$. Error bars denote \pm SEM. $* * * p<0.0001$.

A

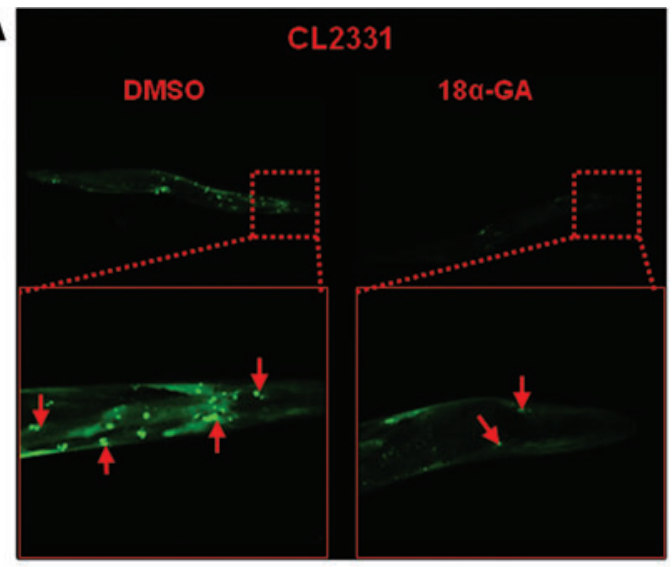

B

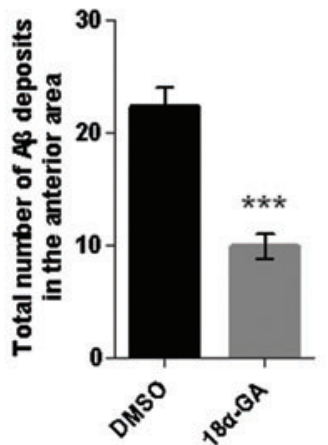

C

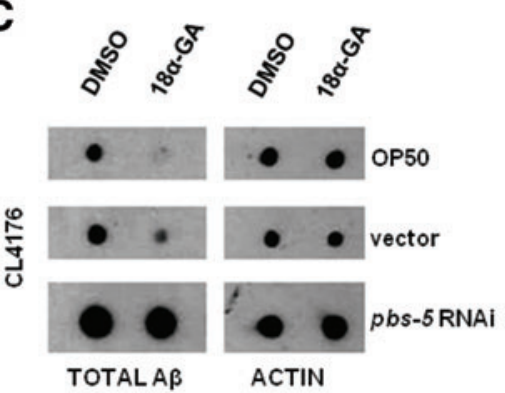

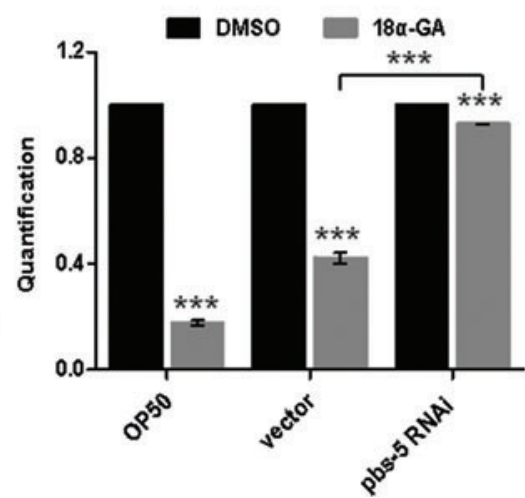

FIG. 5. 18 $\alpha-G A$ reduces A $\beta$ aggregates. (A) Representative fluorescence micrographs of CL2331 strain expressing the $\mathrm{A} \beta_{3-}$ 42 peptide conjugated with GFP treated with $20 \mu \mathrm{g} / \mathrm{ml} 18 \alpha-\mathrm{GA}$ or DMSO for $48 \mathrm{~h}$ and focused images of the same worms in the anterior area. Red arrows indicate amyloid deposits. (B) Total number of amyloid deposits in the anterior area of CL2331 worms treated with $20 \mu \mathrm{g} / \mathrm{ml} 18 \alpha-\mathrm{GA} \quad(n=18)$ or DMSO $(n=16), * * * p<0.0001$. (C) Dot blot analysis and quantification of total $\mathrm{A} \beta$ in CL4176 animals expressing human $\mathrm{A} \beta_{1-42}$ peptide treated with $20 \mu \mathrm{g} / \mathrm{ml} 18 \alpha-\mathrm{GA}$ or DMSO (upper panel-OP50). CL4176 animals were subjected to RNAi for pbs-5 ( $p b s-5$ RNAi) or the empty vector (vector) and were treated with $20 \mu \mathrm{g} / \mathrm{ml} 18 \alpha$-GA or DMSO. Actin was used as a loading control. Error bars denote \pm SEM. To see this illustration in color, the reader is referred to the web version of this article at www .liebertpub.com/ars 
FIG. 6. 18 $\alpha$-GA decreases $A \beta$-induced neuronal death. Percentage (\%) of (A) CT$\mathrm{L}$ proteasome activity (mean value of CT-L activity in DMSO-treated cells set to 100\%), (B1) cell death and survival, and (B2) survival ratio following crystal violet staining of SH-SY5Y neuroblastoma cells exposed to $\mathrm{CM}$ containing human $\mathrm{A} \beta_{1-42}$ peptide and treated with $2 \mu \mathrm{g} / \mathrm{ml} 18 \alpha-\mathrm{GA}$ or DMSO. (C, E) Dot blot analysis and quantification of total $\mathrm{A} \beta$ in (C) SH-SY5Y neuroblastoma cells and (E) murine primary cortical neurons exposed to $\mathrm{CM}$ containing human $\mathrm{A} \beta_{1-}$ 42 peptide and treated with $(\mathbf{C}, \mathbf{E}) 2 \mu \mathrm{g} / \mathrm{ml}$ $18 \alpha$-GA or DMSO or (C) with $2 \mu \mathrm{g} / \mathrm{ml} 18 \alpha-$ GA in the presence of $5 \mu M$ MG132 proteasome inhibitor. GAPDH was used as a loading control. (D1) Representative fluorescence micrographs and (D2) death ratio of murine primary cortical neurons stained with DAPI (dead and alive cells) and EthD-1 (dead cells) exposed to CM containing human $\mathrm{A} \beta_{1-42}$ peptide and treated with $2 \mu \mathrm{g} / \mathrm{ml}$ $18 \alpha-\mathrm{GA}$ or DMSO. Error bars denote \pm $\mathrm{SEM}, * p<0.05, * * p<0.01, * * * p<0.0001$. $\mathrm{CM}$, conditioned medium; DAPI, 4',6diamidino-2-phenylindole; EthD-1, ethidium homodimer. To see this illustration in color, the reader is referred to the web version of this article at www.liebertpub.com/ ars
A
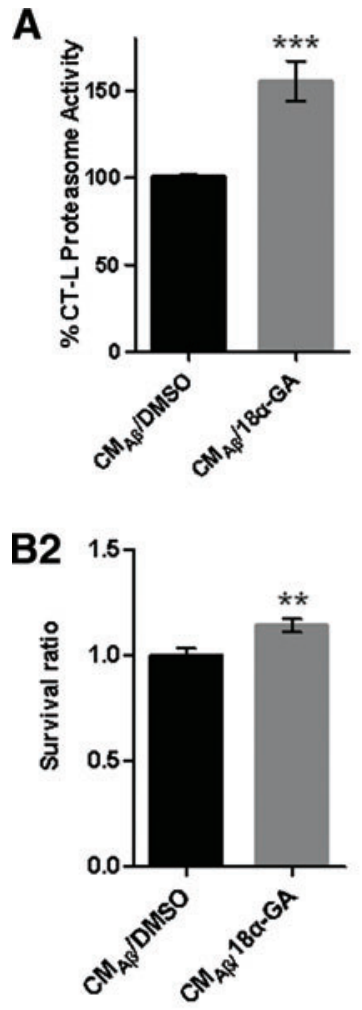

D1

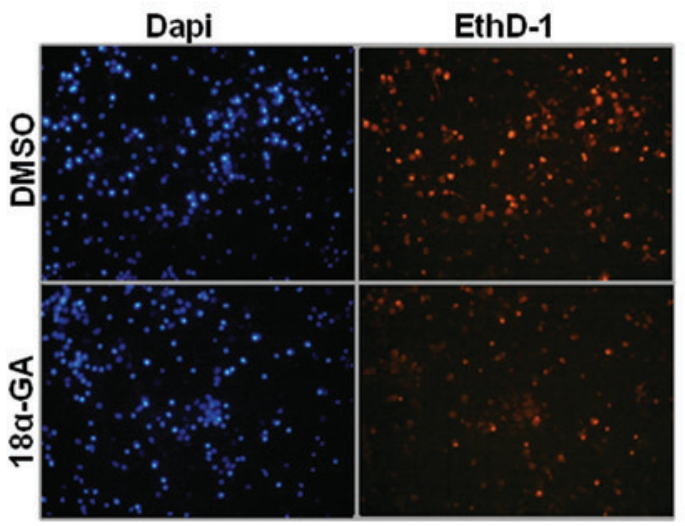

C
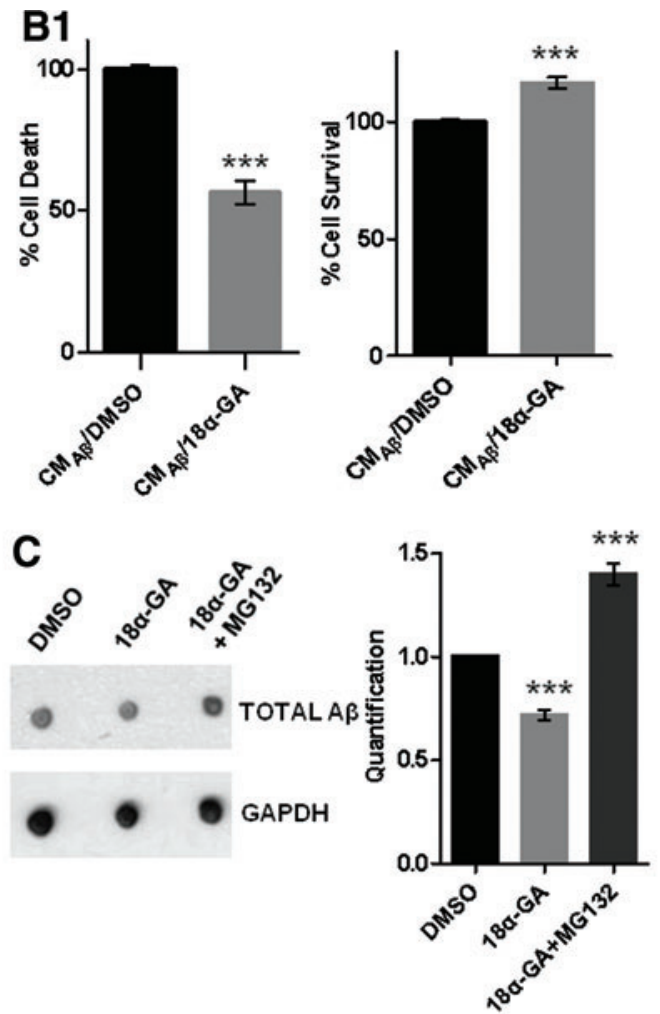

D2

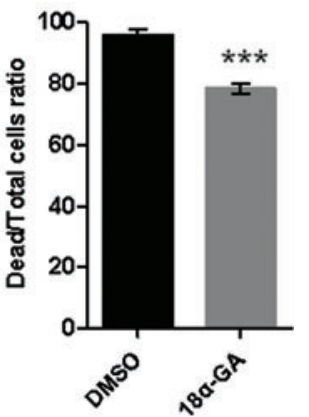

E

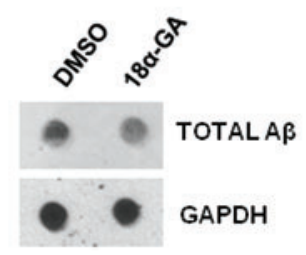

Proteasome function was not tested, but one cannot rule out the possibility of increased proteasomal $\mathrm{A} \beta$ aggregate clearance since oleuropein was previously shown to induce proteasome activation (28). Analogous positive outcomes have been unveiled for several compounds (mainly nutrient derived) in models for other aggregation-related diseases (16), thus pinpointing their potential against aggregation-related pathology.
Our results may adequately coincide with the concept of hormesis; depending on the dose, a substance can be cytoprotective or detrimental for cellular life span. Indeed, we have applied concentrations where absent (Supplementary Fig. S1A), significant (Fig. 2A), or still significant, but less pronounced (compared with the optimum concentration; Supplementary Fig. S1B), life span extension was observed. 
It would not thus be surprising to have a detrimental effect on life span in a higher $18 \alpha-\mathrm{GA}$ concentration. Under the auspice of hormesis, the vitagene system has been suggested as a potential mediator to increase neuroprotection and longevity via a hormetic response $(4,5)$. Cytoprotective heat shock protein 70 (Hsp70), heme oxygenase-1 (HO-1), thioredoxin reductase (Trx), and sirtuins are included in the repertoire of vitagenes. The antioxidant response element induction of HO- 1 and Trx-1 subsequently involves Nrf 2 in the vitagene network. Although some phytochemicals may be beneficial solely due to their direct antioxidant properties, the observed neuroprotection may be also linked to the activation of various hormetic redox-sensitive intracellular cascades, such as the Nrf2 pathway. Our reported positive outcomes of $18 \alpha$ GA-mediated SKN-1/Nrf2 induction can be interpreted under the prism of the vitagene network, while proteasome genes may constitute additional members of this system.

Proteasome activation has been shown to be feasible through manipulation of various UPS components. Given the link between proteasome and longevity, aging, and aggregation-related diseases, its (preferably controlled) activation seems to be an attractive preventive/therapeutic approach. Nevertheless, increased caution should be attributed due to the potential relationship of proteasome activation with cancer risk. Given the manipulation restraints in humans, compound-mediated activation might be the key solution. Diet constituents/active compounds may offer an extra advantage since they are supplied through normal diet from young ages. Consequently, they may block the initial stages of misfolded/damaged/oxidized protein accumulation (for aging) or oligomer/aggregate formation (for AD) before the senescent phenotype is established or before the disease is even triggered, thus being potentially preventive. Moreover, dose-dependent activation may be applicable. Future studies should focus on the identification of such compounds and the delineation of their exact mode of action.

\section{Materials and Methods}

\section{Nematode strains and growth conditions}

Standard procedures were followed for $C$. elegans strain growth and maintenance. All strains were maintained at $20^{\circ} \mathrm{C}$, with the exception of CL4176, CL2331, and CL2179 that were maintained at $16^{\circ} \mathrm{C}$. The following strains were used: N2 [wt Bristol isolate], EU1: skn-1(zu67) IV/nT1[unc?(n754) let-?](IV;V), EU31: skn-1(zu135) IV/nT1[unc?(n754) let-?](IV;V), EU40: skn-1(zu129) IV/nT1[unc-?(n754) let-?](IV;V), CL4176: dvIs27 [pAF29(myo-3/A-Beta1-42/ letUTR) + pRF4(rol-6(su1006))], CL2006: dvIs2[pCL12 (unc-54/human Abeta peptide 1-42 minigene) + pRF4], CL2331: dvIs37 [myo-3p::GFP::A-Beta (3-42) + rol-6 (su1006)], CL2179: dvIs179 [myo-3p::GFP::3' UTR(long) + rol-6(su1006)], LD1: ldIs7 [skn-1B/C::GFP + pRF4(rol6(su1006))], polyubiquitin reporter strain: N2 [Pvha-6::UIM2ZsProSensor], and CF1553: muIs84[pAD76(sod-3::GFP)].

\section{$18 \alpha-G A$ treatment}

$18 \alpha$-GA (Sigma-Aldrich, $\geq 95 \%$ purity) was dissolved as stock solution of $10 \mathrm{mg} / \mathrm{ml}$ in DMSO and stored at $-20^{\circ} \mathrm{C}$. Nematodes were exposed to $20 \mu \mathrm{g} / \mathrm{ml} 18 \alpha-\mathrm{GA}$ or DMSO (control cultures), unless otherwise indicated. Plates containing $18 \alpha$-GA were refreshed every 2 days in life span assays.

\section{Antibodies}

The following antibodies were used in this study: RPN-12 (Enzo Life Sciences; BML-PW8815-0100), RPT-6 (BMLPW8320-0100), PAS-1-7 (BML-PW8195-0100), 6E10 (BioLegend; SIG-39320), actin (MP Biomedicals; 0869100 clone C4), and GAPDH (Santa Cruz, sc-25778). PBS-5 is a homecustomized antibody kindly provided by Prof. Osiewacz.

\section{Life span assay}

Synchronized L4 or young adult animals (80-125 animals per condition) were transferred to fresh nematode growth medium (NGM) plates containing the relative concentration of $18 \alpha-\mathrm{GA}$ or DMSO and day 1 of adulthood was set as $t=0$. The animals were transferred to fresh plates every 2-3 days and examined every day for touch-provoked movement and pharyngeal pumping until death. Each survival assay was repeated at least twice. Survival curves were created using the productlimit method by Kaplan and Meier. The percentage of nematodes remaining alive is plotted against animal age. The logrank (Mantel-Cox) test was used to evaluate differences between survival curves and to determine $p$ values for all independent data. $N$ in life span figures is the number of animals that died over the total number of animals used (the number of animals that died plus the number of censored animals due to internally hatched eggs, extruded gonad, or desiccation due to crawling off the plates). Median life span values are expressed as mean \pm standard error of the mean (SEM).

\section{Paralysis assay}

Synchronized L4 larvae CL2006 animals (100-120 animals per condition) were transferred to NGM plates containing either $18 \alpha-\mathrm{GA}$ or DMSO at $20^{\circ} \mathrm{C}$. Synchronized CL4176 animals (150-300 animals per condition) were transferred to NGM plates containing either $18 \alpha-\mathrm{GA}$ or DMSO at $16^{\circ} \mathrm{C}$ for $48 \mathrm{~h}$ before temperature upshift to $25^{\circ} \mathrm{C}$ for transgene induction. Scoring of paralyzed animals was initiated at day 1 of adulthood for CL2006 strain and 24h after temperature upshift for CL4176 strain. Each paralysis assay was repeated at least thrice. Nematodes were scored as paralyzed if they exhibited halos of cleared bacteria around their heads or failed to undergo half end body wave propagation upon prodding. Animals that died were excluded. The log-rank (Mantel-Cox) test was used to evaluate differences between paralysis curves and to determine $p$ values for all independent data. $N$ in paralysis figures is the number of animals that were paralyzed over the total number of animals used (the number of paralyzed animals plus the number of dead and censored animals). Median paralysis values are expressed as mean \pm SEM.

\section{RNA isolation and real-time polymerase chain reaction analysis}

RNA was extracted from synchronized animals after $72 \mathrm{~h}$ of exposure to $18 \alpha-\mathrm{GA}$ or DMSO and analyzed by standard methods. Primers are summarized in Table 2. Data were analyzed using the comparative $2^{-\Delta \Delta \mathrm{Ct}}$ method and are 
Table 2. Primers Used for Real-Time Polymerase Chain Reaction Analysis

\begin{tabular}{lll}
\hline Gene & \multicolumn{1}{c}{ Reverse primer } & \multicolumn{1}{c}{ Forward primer } \\
\hline pmp-3 & & \multicolumn{1}{c}{ st -4} \\
$g c s-1$ & ACACCGTCGAGAAGCTGTAGA & GTTCCCGTGTTCATCACTCAT \\
$p b s-1$ & AATCACAATATCAGCCCAAGTC & AAGTTGTTGAACCAGCCC \\
$p b s-2$ & TATCATCAGGACCTCCAAGT & CCATCCACGTTTCAAGAATC \\
$p b s-5$ & TGTAGAGGAATTGGCGGA & TGTGCCGTTCTGGATCTG \\
\hline
\end{tabular}

gcs-1, $\gamma$-glutamylcysteine synthetase; gst-4, glutathione $S$-transferase.

presented as the $x$-fold difference in mRNA transcript abundance in $18 \alpha-$ GA-treated animals, normalized to the endogenous pmp-3 gene, relative to DMSO-treated animals.

\section{RNA interference}

The pbs-5 and skn-1 RNAi constructs are from the Ahringer library (23) (Source Bioscience Life Sciences). Synchronized young adult animals (100-120 animals per condition) were transferred to NGM plates containing $2 \mathrm{mM}$ isopropyl-b-D-1-thiogalactopyranoside (IPTG) (Invitrogen) to induce dsRNA expression and seeded with HT115 (DE3) bacteria transformed with either the RNAi-encoding construct or the empty pL4440 vector plus $18 \alpha-$ GA or DMSO.

\section{Phenotypic analysis}

For all assays, N2 animals were allowed to lay eggs for 1520 min on NGM plates containing either $18 \alpha-$ GA or DMSO.

Developmental timing. The progeny were frequently observed to record the needed time to reach the L4 larval stage from egg hatching. The experiment was repeated four times.

Pharyngeal pumping. At day 1 of adulthood, the pharyngeal pumping rate was measured. At least 10 animals per condition were examined.

Defecation assay. At day 1 of adulthood, the defecation rate (period in seconds from defecation to defecation) was measured. At least 20 animals per condition were examined.

Dauer formation. The progeny were kept at $27^{\circ} \mathrm{C}$ and the number of animals at the dauer larval stage over the total number of animals was scored $72 \mathrm{~h}$ later. The experiment was repeated six times.

Fecundity assay. Single N2 L4 larvae were transferred on NGM plates containing either $18 \alpha-$ GA or DMSO. Each animal was transferred every day to a fresh NGM plate containing $18 \alpha-\mathrm{GA}$ or DMSO. Progeny of each animal were scored at L2-L3 larval stage. At least 10 animals per condition were examined.

\section{Oxidative stress resistance assays}

Synchronized L4 larvae N2 animals were exposed to $18 \alpha$ GA or DMSO until day 5 of adulthood. They were then transferred to NGM plates seeded with UV-killed OP50
Escherichia coli containing $2 \mathrm{~m} M$ paraquat (Sigma-Aldrich) and survival was assessed from day 2 to 7 of paraquat exposure. Synchronized N2 animals were exposed to $18 \alpha$-GA or DMSO until day 1 of adulthood and were then exposed to freshly made $80 \mathrm{~m} M$ juglone (Sigma-Aldrich) for $45 \mathrm{~min}$ at $20^{\circ} \mathrm{C}$ and survival was assessed following a 24-h recovery.

\section{Superoxide anion production assay}

$\mathrm{N} 2$ animals were allowed to lay eggs for $2 \mathrm{~h}$ on NGM plates containing $18 \alpha-\mathrm{GA}$, DMSO, or $50 \mu M$ tetracycline (used as positive control). After $96 \mathrm{~h}$, the animals were collected into $1 \%$ Tween 20 in M9 and subjected to sonication; $0.6 \mu M$ phorbol myristate acetate and $0.6 \mathrm{mg} / \mathrm{ml}$ nitro tetrazolium blue (Sigma-Aldrich) were added, followed by incubation at $37^{\circ} \mathrm{C}$ for $30 \mathrm{~min}$. Sample absorbance was measured at $560 \mathrm{~nm}$ using the Safire ${ }^{2}$ Multidetection Microplate Reader (Tecan). The protein content was determined using a Bio-Rad protein assay (Bio-Rad Laboratories). Results are calculated as absorbance units/mg of protein and expressed as \% of control, that is, the percentage of $\mathrm{O}_{2}{ }^{-}$ produced with respect to DMSO-treated animals.

\section{Catalase activity assay}

N2 animals were allowed to lay eggs for 15-20 min on NGM plates containing $18 \alpha-$ GA or DMSO. After $96 \mathrm{~h}$, the animals were collected into $\mathrm{M} / 15$ phosphate buffer, $\mathrm{pH}$ 7.0, and subjected to sonication. The protein content was determined using a Bio-Rad protein assay; $1 \mathrm{ml}$ of substrate solution $(12.5 \mathrm{mM}$ $\mathrm{H}_{2} \mathrm{O}_{2}$ ) was added in $40 \mu \mathrm{g}$ total protein. The cuvette was immediately scanned in a spectrophotometer at $\lambda=240 \mathrm{~nm}$, and the time interval between the optical density from 0.450 to 0.400 was measured. $\mathrm{H}_{2} \mathrm{O}_{2}$-free phosphate buffer was used as control. Catalase activity was calculated based on the rate of $\mathrm{H}_{2} \mathrm{O}_{2}$ decomposition, which is proportional to the absorbance reduction at $\lambda=240 \mathrm{~nm}$, using the equation $k=2.3 / \Delta t \times \log$ $(0.450 / 0.400)$, where $k=$ catalase units and $2.3=$ factor to convert from $\ln$ to $\log$. Results are calculated as absorbance units/mg of protein and expressed as fold catalase activity of control with respect to DMSO-treated animals.

\section{Proteasome peptidase assay}

Animals exposed to $18 \alpha-\mathrm{GA}$ or DMSO for $96 \mathrm{~h}$ were sonicated in proteasome activity lysis buffer $(1 M$ Tris-HCl, $\mathrm{pH}$ 7.6, $100 \mathrm{~m} M$ ATP, $3 \mathrm{M} \mathrm{KCl}, 0.1 M$ ethylenediaminetetraacetic acid, $1 M$ dithiothreitol, $0.2 \%$ Nonidet P- $40,10 \%$ glycerol, $10 \mathrm{mg} / \mathrm{ml}$ aprotinin, and $10 \mathrm{~m} M$ phenylmethylsulfonyl fluoride). CT-L, 
T-L, and PGPH proteasome activities were assayed with the hydrolysis of Suc-LLVY-AMC, Boc-LRR-AMC, and Z-LLEAMC fluorogenic peptides (UBPBio), respectively, for $30 \mathrm{~min}$ at $37^{\circ} \mathrm{C}$. Specific proteasome activity was determined as the difference between the total activity of protein extracts and the remaining activity in the presence of $20 \mu M$ lactacystin (Enzo Life Sciences). Fluorescence was measured using a VersaFluor ${ }^{\mathrm{TM}}$ fluorescence spectrophotometer (Bio-Rad Laboratories).

\section{Proteasome activity in intestinal polyubiquitin reporter animals}

Synchronized transgenic L4 larvae expressing polyubiquitin reporter in the intestine in wt background were exposed to $18 \alpha-$ GA or DMSO until day 1 of adulthood. At indicated time points, they were mounted on a $2 \%$ agarose pad on glass slides and immobilized using $0.1 \mathrm{~m} M$ levamisole. Imaging was performed using a Zeiss AxioImager.Z1 upright epifluorescence microscope (Carl Zeiss Microscopy $\mathrm{GmbH}$ ). Images of whole worms were acquired with $10 \times 0.45$ numerical aperture.

\section{Native gel electrophoresis and in-gel proteasome assay}

$\mathrm{N} 2$ animals were allowed to lay eggs for $2 \mathrm{~h}$ on NGM plates containing either $18 \alpha-\mathrm{GA}$ or DMSO. The progeny were exposed to $18 \alpha-\mathrm{GA}$ or DMSO until the young adult stage and were sonicated in proteasome activity lysis buffer (see above). Forty micrograms of protein was used for native gel electrophoresis of proteasome complexes. CT-L activity was assayed following gel incubation in $50 \mathrm{~m} M$ Tris, $\mathrm{pH} 7.4$, $5 \mathrm{mM} \mathrm{MgCl} 2,1 \mathrm{~m} M$ ATP, and $300 \mu M$ proteasome substrate (Suc-LLVY-AMC) for $30 \mathrm{~min}$ at $37^{\circ} \mathrm{C}$. Proteasome bands were visualized under UV. Part of the lysates was subjected to sodium dodecyl sulfate-polyacrylamide gel electrophoresis (SDS-PAGE), and actin was used as a loading control. Each blot was repeated at least twice.

\section{Immunoblot and dot blot analysis and protein carbonyl group detection}

$\mathrm{N} 2$ animals were allowed to lay eggs for $2 \mathrm{~h}$ on NGM plates containing either $18 \alpha$-GA or DMSO. The progeny were exposed to $18 \alpha-\mathrm{GA}$ or DMSO until the young adult stage (for CL4176 strain and N2) and day 6 of adulthood (for CL2006 strain) and were boiled in nonreducing Laemmli buffer. SDS-PAGE and immunoblotting were performed as described previously (11). For dot blot analysis, 5-10 $\mu \mathrm{g}$ of protein lysates were spotted onto $0.2 \mu \mathrm{m}$ nitrocellulose membranes after soaking into $80^{\circ} \mathrm{C}$ heated tris-buffered saline. Immunoblotting was performed using the $6 \mathrm{E} 10$ antibody that recognizes total $\mathrm{A} \beta$ species. Detection of carbonyl groups into proteins (oxidized proteins) was performed with the Oxyblot protein oxidation detection kit (Millipore Corporation). Each blot was repeated at least twice. Blots were developed with chemiluminescence by using the Clarity ${ }^{\mathrm{TM}}$ Western ECL substrate (Bio-Rad Laboratories). Actin was used as a loading control.

\section{Confocal analysis}

Animals were mounted on 2\% agarose pads on glass slides, anesthetized with $10 \mathrm{~m} M$ levamisole, and observed at room temperature (RT) using a Leica TCS SPE confocal laser scanning microscope (Leica Lasertechnik $\mathrm{GmbH}$ ). The LAS AF software was used for image acquisition. At least 20 animals/ condition in three independent experiments were processed, unless otherwise indicated. For skn-1B/C::GFP localization, synchronized LD1 animals expressing the $\mathrm{p}_{s k n 1} \mathrm{SKN}-1 \mathrm{~b} / \mathrm{c}:: \mathrm{GFP}$ reporter fusion exposed to $18 \alpha-\mathrm{GA}$ or DMSO until day 2 of adulthood were observed. Nematodes were classified into three groups (nuclear, cytoplasmic, intermediate), according to the extent of compartmental GFP distribution in the intestinal cells. For $\mathrm{A} \beta_{3-42}$ deposit measurements, synchronized CL2331 and CL2179 (control strain) animals exposed to $18 \alpha$-GA or DMSO and grown at $20^{\circ} \mathrm{C}$ (to induce aggregation) until day 2 of adulthood were collected. Images of whole worms and focused images in the anterior area of nematodes were acquired with $10 \times 0.45$ and $20 \times 0.70$ numerical aperture, respectively. For GFP levels, synchronized CF1553 animals exposed to $18 \alpha-\mathrm{GA}$ or DMSO until day 1 of adulthood were observed. GFP levels were examined by using a Zeiss AxioImager.Z1 upright epifluorescence microscope. Images of whole worms were acquired with $10 \times 0.45$ numerical aperture.

\section{Cell culture}

The human dopaminergic neuroblastoma cell line, $\mathrm{SH}-$ SY5Y, was maintained in RPMI supplemented with $10 \%$ heat-inactivated fetal bovine serum and $2 \mathrm{~m} M$ glutamine. Murine neurons were isolated from E16.5 C57BL6 embryos, plated onto poly-D-lysine-coated 24-well dishes and maintained in Neurobasal medium (Invitrogen), containing 2\% B27 supplement (Invitrogen) and $0.5 \mathrm{~m} M$ glutamine. SHSY5Y cells and murine cortical neurons were treated with CM produced by (a) the control cell line Chinese hamster ovary (CHO) and (b) the $\mathrm{A} \beta$-producing cell line 7PA2, derived upon stable transfection of $\mathrm{CHO}$ cells with human $\mathrm{APP}_{751}$ bearing the Val717Phe familial AD mutation that leads to $\mathrm{A} \beta$ overproduction (50). Both $\mathrm{CHO}$ and $\mathrm{CHO}-7 \mathrm{PA} 2$ cell lines were maintained in Dulbecco's Modified Eagle's Medium (DMEM) supplemented with 10\% heat-inactivated fetal bovine serum, $2 \mathrm{~m} M$ glutamine, and $1 \%$ nonessential amino acids (complete medium), with or without G418 (200 $\mu \mathrm{g} / \mathrm{ml}$, Invitrogen). SH-SY5Y cells and murine cortical neurons were exposed to $2 \mu \mathrm{g} / \mathrm{ml} 18 \alpha$-GA or DMSO in addition to the relative $\mathrm{CM}$ derived from 7PA2 cells $\left(\mathrm{CM}_{\mathrm{A} \beta}\right)$ or $\mathrm{CHO}$ cells $\left(\mathrm{CM}_{\text {control }}\right)$. All cultures were maintained at $37^{\circ} \mathrm{C}$ in a $5 \% \mathrm{CO}_{2}$ humidified incubator.

$\mathrm{CM}$ preparation. $\mathrm{CHO}$ and 7PA2 cells were grown to $\sim 90 \%$ confluency, washed with phosphate-buffered saline (PBS), and incubated in serum-free DMEM for $\sim 16 \mathrm{~h}$. The $\mathrm{CM}$ was collected and centrifuged to clear cell debris.

Cell death/viability assay. Cell death/viability of SHSY5Y cultures was assessed through scoring of (a) detached cells in the supernatant from the CM-treated SH-SY5Y cells (cell death analysis) and (b) attached CM-treated SH-SY5Y cells (cell viability) after $2 \mathrm{~h}$ of incubation in triplicates using a Coulter $Z_{2}$ counter. Cell death of cortical neurons was assessed through labeling of necrotic cells. Neurons treated as described above for $1 \mathrm{~h}$ were stained with $0.2 \mu M$ ethidium homodimer (nuclei labeling of dead or dying cells, Thermofisher Scientific) and $1 \mu \mathrm{g} / \mathrm{ml} 4^{\prime}, 6$-diamidino-2-phenylindole (nuclei 
labeling of dead and alive cells; Vector Laboratories) for $20 \mathrm{~min}$ at $37^{\circ} \mathrm{C}$. Cultures were then fixed in $4 \%$ paraformaldehyde for $20 \mathrm{~min}$ and washed with PBS. Dye uptake was analyzed using a Nikon ECLIPSE TE200 inverted fluorescent microscope (Nikon). Digital images were captured with an Olympus SP-510U2 camera (Olympus). Images were processed using the Image J $1.48 \mathrm{v}$.

Survival ratio through crystal violet staining. SH-SY5Y cells treated as described above were fixed in $4 \%$ paraformaldehyde for $20 \mathrm{~min}$ and then stained with $0.2 \%$ crystal violet in distilled water. Cells were washed with water, airdried, and the dye was eluted with $30 \%$ acetic acid. Viability was assessed by measuring dye absorbance at $595 \mathrm{~nm}$ using the Safire ${ }^{2}$ Multidetection Microplate Reader.

\section{Statistical analysis}

Statistical analysis and graphs were produced using Prism (GraphPad Software, Inc.) and Microsoft Office 2003 Excel (Microsoft Corporation) software packages. Data in all assays (including blot quantification) are depicted as the average of three independent experiments (unless otherwise indicated). Error bars denote \pm SEM. Student's $t$-test was used for comparisons. Asterisks denote $p$-values as follows: $* p<0.05, * * p<0.01, * * * p<0.001$, not significant. Quantification of the ratio of each protein to actin/GAPDH (using the ImageJ software) and normalization to control appear next to each representative native gel/blot.

\section{Acknowledgments}

The authors are grateful to Prof. Osiewacz and Dr. Kletsas for antibodies; to Dr. Bano for reagents; to Dr. Vekrellis and his group for the isolation of cortical neurons and reagents; and to Dr. Link for CL2331 and CL2179 strains. Nematode strains used in this study were provided by the Caenorhabditis Genetics Center, supported by the U.S. National Institutes of Health National Center for Research Resources. This work was funded by two Research Funding Programs: Thales GenAge [QALHS AP:10479/3.7.12 MIS380228] (to E.S.G. and N.C.) and MAESTRO (to N.C.) cofinanced by the European Union (European Social Fund) and Greek national funds through the Operational Program, Education and Lifelong Learning, of the National Strategic Reference Framework (NSRF), a European Union (266486 NU-AGE) grant (to E.S.G.), an IKYDA 2012 fellowship, an Empirikion Foundation Scientific Project and a Scientific Project funded by John S. Latsis Public Benefit Foundation (to N.C.), and by the Academy of Finland (259797 to C.I.H.). The present publication is supported by the COST Actions PROTEOSTASIS BM1307 and GENiE BM1408, supported by COST (European Cooperation in Science and Technology).

\section{Author Disclosure Statement}

No competing financial interests exist.

\section{References}

1. Adachi H, Fujiwara Y, and Ishii N. Effects of oxygen on protein carbonyl and aging in Caenorhabditis elegans mutants with long (age-1) and short (mev-1) life spans. J Gerontol A Biol Sci Med Sci 53: B240-B244, 1998.
2. Alavez S, Vantipalli MC, Zucker DJ, Klang IM, and Lithgow GJ. Amyloid-binding compounds maintain protein homeostasis during ageing and extend lifespan. Nature 472: 226-229, 2011.

3. Bishop NA and Guarente L. Two neurons mediate dietrestriction-induced longevity in C. elegans. Nature 447: 545-549, 2007.

4. Calabrese V, Cornelius C, Dinkova-Kostova AT, Calabrese EJ, and Mattson MP. Cellular stress responses, the hormesis paradigm, and vitagenes: novel targets for therapeutic intervention in neurodegenerative disorders. Antioxid Redox Signal 13: 1763-1811, 2010.

5. Calabrese V, Cornelius C, Dinkova-Kostova AT, Iavicoli I, Di Paola R, Koverech A, Cuzzocrea S, Rizzarelli E, and Calabrese EJ. Cellular stress responses, hormetic phytochemicals and vitagenes in aging and longevity. Biochim Biophys Acta 1822: 753-783, 2012.

6. Chakrabortee S, Liu Y, Zhang L, Matthews HR, Zhang H, Pan N, Cheng CR, Guan SH, Guo DA, Huang Z, Zheng Y, and Tunnacliffe A. Macromolecular and small-molecule modulation of intracellular Abeta42 aggregation and associated toxicity. Biochem J 442: 507-515, 2012.

7. Chen Q, Thorpe J, Dohmen JR, Li F, and Keller JN. Ump1 extends yeast lifespan and enhances viability during oxidative stress: central role for the proteasome? Free Radic Biol Med 40: 120-126, 2006.

8. Chondrogianni N, Georgila K, Kourtis N, Tavernarakis N, and Gonos ES. 20S proteasome activation promotes life span extension and resistance to proteotoxicity in Caenorhabditis elegans. FASEB J 29: 611-622, 2015.

9. Chondrogianni $\mathrm{N}$ and Gonos ES. Proteasome activation as a novel antiaging strategy. IUBMB Life 60: 651-655, 2008.

10. Chondrogianni N, Kapeta S, Chinou I, Vassilatou K, Papassideri I, and Gonos ES. Anti-ageing and rejuvenating effects of quercetin. Exp Gerontol 45: 763-771, 2010.

11. Chondrogianni N, Petropoulos I, Franceschi C, Friguet B, and Gonos ES. Fibroblast cultures from healthy centenarians have an active proteasome. Exp Gerontol 35: 721-728, 2000.

12. Chondrogianni N, Sakellari M, Lefaki M, Papaevgeniou N, and Gonos ES. Proteasome activation delays aging in vitro and in vivo. Free Radic Biol Med 71: 303-320, 2014.

13. Chondrogianni N, Stratford FL, Trougakos IP, Friguet B, Rivett AJ, and Gonos ES. Central role of the proteasome in senescence and survival of human fibroblasts: induction of a senescence-like phenotype upon its inhibition and resistance to stress upon its activation. J Biol Chem 278: 2802628037, 2003.

14. Chondrogianni N, Trougakos IP, Kletsas D, Chen QM, and Gonos ES. Partial proteasome inhibition in human fibroblasts triggers accelerated M1 senescence or M2 crisis depending on p53 and Rb status. Aging Cell 7: 717-732, 2008.

15. Chondrogianni N, Tzavelas C, Pemberton AJ, Nezis IP, Rivett AJ, and Gonos ES. Overexpression of proteasome beta5 assembled subunit increases the amount of proteasome and confers ameliorated response to oxidative stress and higher survival rates. J Biol Chem 280: 11840-11850, 2005.

16. Chondrogianni N, Voutetakis K, Kapetanou M, Delitsikou V, Papaevgeniou N, Sakellari M, Lefaki M, Filippopoulou $\mathrm{K}$, and Gonos ES. Proteasome activation: an innovative promising approach for delaying aging and retarding agerelated diseases. Ageing Res Rev 23 (Pt A): 37-55, 2015. 
17. Crook-McMahon HM, Olahova M, Button EL, Winter JJ, and Veal EA. Genome-wide screening identifies new genes required for stress-induced phase 2 detoxification gene expression in animals. BMC Biol 12: 64, 2014.

18. Deusing DJ, Winter S, Kler A, Kriesl E, Bonnlander B, Wenzel U, and Fitzenberger E. A catechin-enriched green tea extract prevents glucose-induced survival reduction in Caenorhabditis elegans through sir- 2.1 and uba- 1 dependent hormesis. Fitoterapia 102: 163-170, 2015.

19. Diomede L, Rigacci S, Romeo M, Stefani M, and Salmona M. Oleuropein aglycone protects transgenic $C$. elegans strains expressing Abeta42 by reducing plaque load and motor deficit. PLoS One 8: e58893, 2013.

20. Drake J, Link CD, and Butterfield DA. Oxidative stress precedes fibrillar deposition of Alzheimer's disease amyloid beta-peptide $(1-42)$ in a transgenic Caenorhabditis elegans model. Neurobiol Aging 24: 415-420, 2003.

21. Fitzenberger E, Deusing DJ, Marx C, Boll M, Luersen K, and Wenzel $\mathrm{U}$. The polyphenol quercetin protects the mev1 mutant of Caenorhabditis elegans from glucose-induced reduction of survival under heat-stress depending on SIR2.1, DAF-12, and proteasomal activity. Mol Nutr Food Res 58: 984-994, 2014.

22. Fitzenberger E, Deusing DJ, Wittkop A, Kler A, Kriesl E, Bonnlander B, and Wenzel U. Effects of plant extracts on the reversal of glucose-induced impairment of stressresistance in Caenorhabditis elegans. Plant Foods Hum Nutr 69: 78-84, 2014.

23. Fraser AG, Kamath RS, Zipperlen P, Martinez-Campos M, Sohrmann M, and Ahringer J. Functional genomic analysis of $C$. elegans chromosome I by systematic RNA interference. Nature 408: 325-330, 2000.

24. Grossi C, Ed Dami T, Rigacci S, Stefani M, Luccarini I, and Casamenti F. Employing Alzheimer disease animal models for translational research: focus on dietary components. Neurodegener Dis 13: 131-134, 2014.

25. Inoue $\mathrm{H}$, Hisamoto $\mathrm{N}$, An $\mathrm{JH}$, Oliveira RP, Nishida $\mathrm{E}$, Blackwell TK, and Matsumoto K. The C. elegans p38 MAPK pathway regulates nuclear localization of the transcription factor SKN-1 in oxidative stress response. Genes Dev 19: 2278-2283, 2005.

26. Kahn NW, Rea SL, Moyle S, Kell A, and Johnson TE. Proteasomal dysfunction activates the transcription factor SKN-1 and produces a selective oxidative-stress response in Caenorhabditis elegans. Biochem J 409: 205-213, 2008.

27. Kapeta S, Chondrogianni N, and Gonos ES. Nuclear erythroid factor 2-mediated proteasome activation delays senescence in human fibroblasts. $J$ Biol Chem 285: 81718184, 2010.

28. Katsiki M, Chondrogianni N, Chinou I, Rivett AJ, and Gonos ES. The olive constituent oleuropein exhibits proteasome stimulatory properties in vitro and confers life span extension of human embryonic fibroblasts. $R e$ juvenation Res 10: 157-172, 2007.

29. Keller JN, Hanni KB, and Markesbery WR. Impaired proteasome function in Alzheimer's disease. J Neurochem 75: 436-439, 2000.

30. Kenyon C. The plasticity of aging: insights from long-lived mutants. Cell 120: 449-460, 2005.

31. Kimura M, Inoue H, Hirabayashi K, Natsume H, and Ogihara M. Glycyrrhizin and some analogues induce growth of primary cultured adult rat hepatocytes via epidermal growth factor receptors. Eur J Pharmacol 431: 151-161, 2001.
32. Kruegel U, Robison B, Dange T, Kahlert G, Delaney JR, Kotireddy S, Tsuchiya M, Tsuchiyama S, Murakami CJ, Schleit J, Sutphin G, Carr D, Tar K, Dittmar G, Kaeberlein M, Kennedy BK, and Schmidt M. Elevated proteasome capacity extends replicative lifespan in Saccharomyces cerevisiae. PLoS Genet 7: e1002253, 2011.

33. Kwak MK, Cho JM, Huang B, Shin S, and Kensler TW. Role of increased expression of the proteasome in the protective effects of sulforaphane against hydrogen peroxide-mediated cytotoxicity in murine neuroblastoma cells. Free Radic Biol Med 43: 809-817, 2007.

34. Kwak MK, Wakabayashi N, Greenlaw JL, Yamamoto M, and Kensler TW. Antioxidants enhance mammalian proteasome expression through the Keap1-Nrf2 signaling pathway. Mol Cell Biol 23: 8786-8794, 2003.

35. Li X, Matilainen O, Jin C, Glover-Cutter KM, Holmberg CI, and Blackwell TK. Specific SKN-1/Nrf stress responses to perturbations in translation elongation and proteasome activity. PLoS Genet 7: e1002119, 2011.

36. Link CD. Expression of human beta-amyloid peptide in transgenic Caenorhabditis elegans. Proc Natl Acad Sci U S A 92: 9368-9372, 1995.

37. Lopez-Otin C, Blasco MA, Partridge L, Serrano M, and Kroemer G. The hallmarks of aging. Cell 153: 1194-1217, 2013.

38. Mannhaupt G, Schnall R, Karpov V, Vetter I, and Feldmann H. Rpn4p acts as a transcription factor by binding to PACE, a nonamer box found upstream of $26 \mathrm{~S}$ proteasomal and other genes in yeast. FEBS Lett 450: 27-34, 1999.

39. Marambaud $P$, Zhao H, and Davies P. Resveratrol promotes clearance of Alzheimer's disease amyloid-beta peptides. J Biol Chem 280: 37377-37382, 2005.

40. Matilainen O, Arpalahti L, Rantanen V, Hautaniemi S, and Holmberg CI. Insulin/IGF-1 signaling regulates proteasome activity through the deubiquitinating enzyme UBH-4. Cell Rep 3: 1980-1995, 2013.

41. Matsui S, Matsumoto H, Sonoda Y, Ando K, Aizu-Yokota E, Sato T, and Kasahara T. Glycyrrhizin and related compounds down-regulate production of inflammatory chemokines IL-8 and eotaxin 1 in a human lung fibroblast cell line. Int Immunopharmacol 4: 1633-1644, 2004.

42. Myeku N, Clelland CL, Emrani S, Kukushkin NV, Yu WH, Goldberg AL, and Duff KE. Tau-driven 26S proteasome impairment and cognitive dysfunction can be prevented early in disease by activating cAMP-PKA signaling. Nat Med 22: 46-53, 2016.

43. Niccoli $\mathrm{T}$ and Partridge L. Ageing as a risk factor for disease. Curr Biol 22:R741-R752, 2012.

44. Olahova M, Taylor SR, Khazaipoul S, Wang J, Morgan BA, Matsumoto K, Blackwell TK, and Veal EA. A redoxsensitive peroxiredoxin that is important for longevity has tissue- and stress-specific roles in stress resistance. Proc Natl Acad Sci U S A 105: 19839-19844, 2008.

45. Oliveira RP, Porter Abate J, Dilks K, Landis J, Ashraf J, Murphy CT, and Blackwell TK. Condition-adapted stress and longevity gene regulation by Caenorhabditis elegans SKN-1/Nrf. Aging Cell 8: 524-541, 2009.

46. Papaevgeniou $\mathrm{N}$ and Chondrogianni $\mathrm{N}$. The ubiquitin proteasome system in Caenorhabditis elegans and its regulation. Redox Biol 2: 333-347, 2014.

47. Paul S. Dysfunction of the ubiquitin-proteasome system in multiple disease conditions: therapeutic approaches. Bioessays 30: 1172-1184, 2008. 
48. Perez VI, Buffenstein R, Masamsetti V, Leonard S, Salmon AB, Mele J, Andziak B, Yang T, Edrey Y, Friguet B, Ward W, Richardson A, and Chaudhuri A. Protein stability and resistance to oxidative stress are determinants of longevity in the longest-living rodent, the naked mole-rat. Proc Natl Acad Sci U S A 106: 3059-3064, 2009.

49. Pickering AM and Davies KJ. A simple fluorescence labeling method for studies of protein oxidation, protein modification, and proteolysis. Free Radic Biol Med 52: 239-246, 2012.

50. Podlisny MB, Ostaszewski BL, Squazzo SL, Koo EH, Rydell RE, Teplow DB, and Selkoe DJ. Aggregation of secreted amyloid beta-protein into sodium dodecyl sulfatestable oligomers in cell culture. J Biol Chem 270: 95649570, 1995.

51. Regitz C, Fitzenberger E, Mahn FL, Dussling LM, and Wenzel U. Resveratrol reduces amyloid-beta (Abeta)induced paralysis through targeting proteostasis in an Alzheimer model of Caenorhabditis elegans. Eur J Nutr 55: 741-747, 2015.

52. Regitz C and Wenzel U. Amyloid-beta (Abeta1-42)-induced paralysis in Caenorhabditis elegans is reduced by restricted cholesterol supply. Neurosci Lett 576: 93-96, 2014.

53. Rodriguez KA, Edrey YH, Osmulski P, Gaczynska M, and Buffenstein R. Altered composition of liver proteasome assemblies contributes to enhanced proteasome activity in the exceptionally long-lived naked mole-rat. PLoS One 7: e35890, 2012.

54. Rossi T, Castelli M, Zandomeneghi G, Ruberto A, Benassi L, Magnoni C, Santachiara S, and Baggio G. Selectivity of action of glycyrrhizin derivatives on the growth of MCF-7 and HEP-2 cells. Anticancer Res 23: 3813-3818, 2003.

55. Tonoki A, Kuranaga E, Tomioka T, Hamazaki J, Murata S, Tanaka K, and Miura M. Genetic evidence linking agedependent attenuation of the $26 \mathrm{~S}$ proteasome with the aging process. Mol Cell Biol 29: 1095-1106, 2009.

56. Tullet JM, Hertweck M, An JH, Baker J, Hwang JY, Liu S, Oliveira RP, Baumeister R, and Blackwell TK. Direct inhibition of the longevity-promoting factor SKN-1 by insulinlike signaling in C. elegans. Cell 132: 1025-1038, 2008.

57. Upadhya SC and Hegde AN. Role of the ubiquitin proteasome system in Alzheimer's disease. BMC Biochem 8 Suppl 1: S12, 2007.

58. Vilchez D, Morantte I, Liu Z, Douglas PM, Merkwirth C, Rodrigues AP, Manning G, and Dillin A. RPN-6 determines $C$. elegans longevity under proteotoxic stress conditions. Nature 489: 263-268, 2012.

59. Weissman AM, Shabek N, and Ciechanover A. The predator becomes the prey: regulating the ubiquitin system by ubiquitylation and degradation. Nat Rev Mol Cell Biol 12: 605-620, 2011.

60. Wong A, Boutis P, and Hekimi S. Mutations in the clk-1 gene of Caenorhabditis elegans affect developmental and behavioral timing. Genetics 139: 1247-1259, 1995.

61. Zong L, Qu Y, Xu MY, Dong YW, and Lu LG. 18alphaglycyrrhetinic acid extracted from Glycyrrhiza radix inhibits proliferation and promotes apoptosis of the hepatic stellate cell line. J Dig Dis 14: 328-336, 2013.
Address correspondence to:

Dr. Niki Chondrogianni Institute of Biology

Medicinal Chemistry and Biotechnology National Hellenic Research Foundation 48 Vassileos Constantinou Avenue Athens 11635

Greece

E-mail: nikichon@eie.gr

Date of first submission to ARS Central, September 8, 2015; date of final revised submission, January 21, 2016; date of acceptance, February 11, 2016.

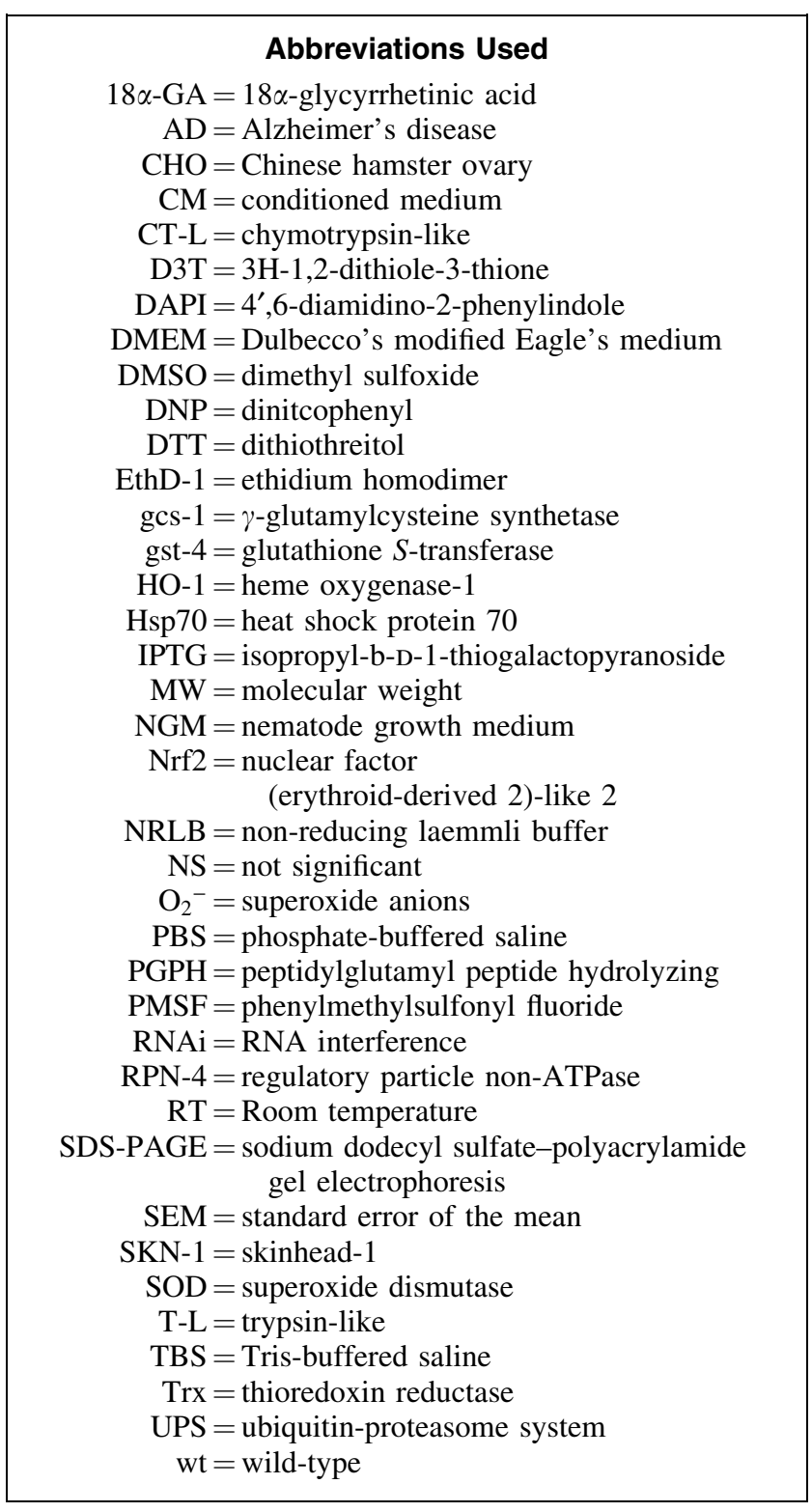

